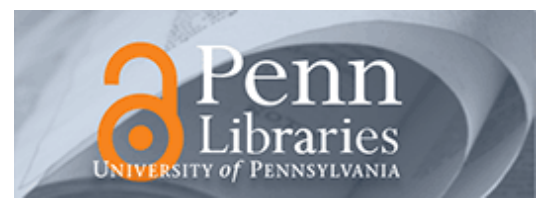

University of Pennsylvania

ScholarlyCommons

Finance Papers

Wharton Faculty Research

8-2015

\title{
Good and Bad Uncertainty: Macroeconomic and Financial Market Implications
}

\author{
Gill Segal \\ University of Pennsylvania \\ Ivan Shaliastovich \\ University of Pennsylvania \\ Amir Yaron \\ University of Pennsylvania
}

Follow this and additional works at: https://repository.upenn.edu/fnce_papers

Part of the Finance and Financial Management Commons, and the Growth and Development Commons

\section{Recommended Citation}

Segal, G., Shaliastovich, I., \& Yaron, A. (2015). Good and Bad Uncertainty: Macroeconomic and Financial Market Implications. Journal of Financial Economics, 117 (2), 369-397. http://dx.doi.org/10.1016/ j.jfineco.2015.05.004

This paper is posted at ScholarlyCommons. https://repository.upenn.edu/fnce_papers/211

For more information, please contact repository@pobox.upenn.edu. 


\title{
Good and Bad Uncertainty: Macroeconomic and Financial Market Implications
}

\begin{abstract}
Does macroeconomic uncertainty increase or decrease aggregate growth and asset prices? To address this question, we decompose aggregate uncertainty into 'good' and 'bad' volatility components, associated with positive and negative innovations to macroeconomic growth. We document that in line with our theoretical framework, these two uncertainties have opposite impact on aggregate growth and asset prices. Good uncertainty predicts an increase in future economic activity, such as consumption, output, and investment, and is positively related to valuation ratios, while bad uncertainty forecasts a decline in economic growth and depresses asset prices. Further, the market price of risk and equity beta of good uncertainty are positive, while negative for bad uncertainty. Hence, both uncertainty risks contribute positively to risk premia, and help explain the cross-section of expected returns beyond cash flow risk.
\end{abstract}

\section{Keywords}

uncertainty, economic growth, asset prices, recursive utility

Disciplines

Economics | Finance and Financial Management | Growth and Development 


\title{
Good and Bad Uncertainty:
}

\section{Macroeconomic and Financial Market Implications}

\author{
Gill Segal, Ivan Shaliastovich, Amir Yaron * \\ First Draft: May 2013 \\ Current Draft: January 2014
}

\begin{abstract}
Does macroeconomic uncertainty increase or decrease aggregate growth and asset prices? To address this question, we decompose aggregate uncertainty into 'good' and 'bad' volatility components, associated with positive and negative innovations to macroeconomic growth. We document that in line with our theoretical framework, these two uncertainties have opposite impact on aggregate growth and asset prices. Good uncertainty predicts an increase in future economic activity, such as consumption, output, and investment, and is positively related to valuation ratios, while bad uncertainty forecasts a decline in economic growth and depresses asset prices. Further, the market price of risk and equity beta of good uncertainty are positive, while negative for bad uncertainty. Hence, both uncertainty risks contribute positively to risk premia, and help explain the cross-section of expected returns beyond cash flow risk.
\end{abstract}

*Gill Segal (segalg@wharton.upenn.edu) and Ivan Shaliastovich (ishal@wharton.upenn.edu) are at The Wharton School, University of Pennsylvania, and Amir Yaron (yarona@wharton.upenn.edu) is at The Wharton School, University of Pennsylvania and NBER. We thank participants at 2014 AEA Meeting, 2013 Minnesota Macro-Asset Pricing Conference, 2013 Tepper-LAEF Conference, University of Chicago Conference Honoring Lars Hansen, BI Norwegian Business School, LBS, LSE, University of Frankfurt, University of Notre-Dame, Wharton, for their comments and suggestions. Shaliastovich and Yaron thank Jacobs Levy Equity Management Center for Quantitative Financial Research for financial support. 


\section{Introduction}

How do changes in economic uncertainty affect macroeconomic quantities and asset prices? We show that the answer to this question hinges on the type of uncertainty one considers. 'Bad' uncertainty is the volatility that is associated with negative innovations to macroeconomic quantities (e.g., output, consumption, earnings), and with lower prices and investment, while 'good' uncertainty is the volatility that is associated with positive shocks to these variables, and with higher asset prices and investment.

To illustrate these two types of uncertainties, it is instructive to consider two episodes: (i) the high-tech revolution of early-mid 1990's, and (ii) the recent collapse of Lehman brothers in the fall of 2008. In the first case, and with the introduction of the world-wide-web, a common view was that this technology would provide many positive growth opportunities that would enhance the economy, yet it was unknown by how much? We refer to such a situation as 'good' uncertainty. Alternatively, the second case marked the beginning of the global financial crisis, and with many of the ensuing bankruptcy cases one knew that the state of economy was deteriorating - yet, again, it was not clear by how much? We consider this situation as a rise in 'bad' uncertainty. In both cases, uncertainty level rises relative to its long-run steady-state level, yet, the first case coincides with an optimistic view, and the second with a pessimistic one.

In this paper, we demonstrate that variations in good and bad uncertainty have separate and significant opposing impacts on the real economy and asset prices. We use an extended version of the Long Run Risks model of Bansal and Yaron (2004) to theoretically show conditions under which good and bad uncertainty have different impact on prices. To make a meaningful distinction between good and bad uncer-

tainty, we decompose, within the model, the overall shocks to consumption into two separate zero-mean components which capture positive and negative growth innovations. The volatilities of these two shocks are time varying, and capture uncertainty fluctuations associated with the positive and negative parts of the distribution of consumption growth. Thus, in the model, valuation ratios are driven by three state variables: predictable consumption growth, good uncertainty, and bad uncertainty. Consequently, the stochastic discount factor, and therefore risk premia, are deter- 
mined by three sources of risk: cash flow, good uncertainty, and bad uncertainty risks.

We show that with preferences for early resolution of uncertainty, the direct impact of both types of uncertainty shocks is to reduce prices. For prices to rise in response to a good uncertainty shock there has to be an explicit positive link between good uncertainty and future growth prospects - a feature that we impose in our benchmark model ${ }^{1}$. As a consequence of these two effects, prices respond more (in absolute value) to a negative shock than to a comparable sized positive uncertainty shock. We further show that the market price of good uncertainty risk and its equity beta have the same (positive) sign. Thus, even though prices can rise in response to good uncertainty, it commands a positive risk premium.

Overall the model key empirical implications include: (i) good uncertainty positively predicts future measures of economic activity, while bad uncertainty negatively forecasts future economic growth; (ii) good uncertainty fluctuations are positively related to asset valuations and to the real risk-free rate, while an increase in bad uncertainty depresses asset prices and the riskless yield; and (iii) the shocks to good and bad uncertainty carry positive and negative market prices of risk, respectively, yet both contribute positively to the risk premium. ${ }^{2}$

We evaluate our model empirical implications by utilizing a novel econometric approach to identify good and bad uncertainty (see Barndorff-Nielsen, Kinnebrock, and Shephard (2010)). Empirically, we use the ex-ante (predictable) components of the positive and negative realized semivariances of industrial production growth rate as the respective proxies for good and bad uncertainty ${ }^{3}$ In its limiting behavior, positive (negative) semivariance captures one-half of the variation in any Gaussian symmetric movements in the growth rate of the variable of interest, as well as the variation of any non-Gaussian positive (negative) component in it. Thus, in our empirical work the positive (negative) semivariance captures the volatility component that is associated with the positive (negative) part of the total variation of industrial

\footnotetext{
${ }^{1}$ Backus, Routledge, and Zin (2010) also feature a direct feedback from volatility to future growth. However, they focus on total volatility and show the importance of this feedback for reconciling various lead-lag correlations between consumption growth and market returns.

${ }^{2}$ Although both uncertainties carry positive risk premium, their covariance, which may capture a common component, could contribute negatively to the risk premium.

${ }^{3} \mathrm{We}$ use industrial production because high-frequency real consumption data is not available for the long sample.
} 
production growth, and its predictive component corresponds to the model concept for good (bad) uncertainty.

Consistent with the model, we document in the data that across various macroeconomic growth rates, and across various horizons, good economic uncertainty positively predicts future growth. This evidence includes growth for horizons of one to five years in consumption, output, investment, R\&D, market earnings and dividends. Similarly, we find a negative relationship between bad uncertainty and future growth rates of these macro variables. Together, these findings support the model feedback channel from macroeconomic uncertainty to future growth rates. Quantitatively, the impact of uncertainty has a large economic effect on the macro variables. For example, the GDP growth increases by about $2.5 \%$ one year after a one standard deviation shock to good uncertainty, and this positive effect persists over the next three years. On the other hand, bad uncertainty shocks decrease output growth by about $1.3 \%$ one year after and their effects remain negative for several years. The responses of investment and R\&D to these shocks are even stronger. Both capital and R\&D investment significantly increase with good uncertainty and remain positive five years out, while they significantly drop with a shock to bad uncertainty. An implication of the offsetting responses to good and bad uncertainty is that the measured responses to overall uncertainty are going to be muted. Indeed, GDP growth declines only by about $0.25 \%$ after a shock to total uncertainty. The response to total uncertainty is significantly weaker than that to bad uncertainty, which underscores the potential importance of decomposing uncertainty into good and bad components.

The empirical evidence in the data is further consistent with the model's key asset-pricing implications. We document that the market price-dividend ratio and the risk-free rate appreciate with good uncertainty and decline with bad uncertainty. Quantitatively, the market log price-dividend ratio rises by about 0.07 one year out in response to a one standard deviation shock to good uncertainty and remains positive ten years afterward. Bad uncertainty shock depresses the log price-dividend ratio by 0.06 on impact and remains negative for ten years out. Similarly to the macroeconomic growth rates, the response of the price-dividend ratio to total uncertainty is negative, but is understated relative to the response to bad uncertainty. The evidence for the response of the price-earnings ratio is very similar to that of the price-dividend ratio. 
Finally, using the cross-section of 21 returns that include the market as well as the ten book-to-market and ten size-sorted portfolios, we show that the market price of risk is positive for good uncertainty, while it is negative for bad uncertainty. Moreover, the market and equity portfolios have a positive exposure (beta) to good uncertainty risk, and a negative exposure to bad uncertainty risk. Consequently, both good and bad uncertainty command a positive risk premium, although the interaction of their shocks can contribute negatively to the total risk compensation, since the good and bad uncertainty shocks are positively correlated. The model performs quite well in the cross-section: the market risk premium is $7.6 \%$ in the data relative to $7.7 \%$ in the model; the value spreads are $6.6 \%$ and $5.6 \%$ in the data and model, respectively, and the model-implied size spread is $7.4 \%$ relative to $8.9 \%$ in the data.

Related Literature. Our paper is related to a growing theoretical and empirical literature that documents the connection between economic uncertainty, aggregate quantities, and asset prices. Our concept of economic uncertainty refers to the time series volatility of the fundamental shocks to the economic variable of interest (e.g., consumption and GDP growth). This is distinct from other aspects of uncertainty, such as parameter uncertainty, learning, robust-control, and ambiguity (see discussions in Pastor and Veronesi (2009), Hansen and Sargent (2010), Epstein and Schneider (2010)). While there is a long standing and voluminous literature on the time-varying second moments in asset returns, the evidence for time variation in the second moments of macro aggregates, such as consumption, dividends, earnings, investment, and output, is more limited and recent. Kandel and Stambaugh (1991) is an early paper providing evidence for stochastic volatility in consumption growth. More recently, McConnell and Perez-Quiros (2000), Stock and Watson (2002), and Bansal, Khatchatrian, and Yaron (2005b) provide supporting evidence that volatility measures based on macro aggregates feature persistent predictable variation. Related, Bloom (2009) shows that the effect of increased aggregate volatility leads to an immediate drop in consumption and output growth rates as firms delay their investment decisions.

The evidence on time-varying volatility of macro aggregates has also instilled recent interest in examining the role of uncertainty in production/DSGE models, with generally an emphasis on a negative relationship between growth and uncertainty - see Ramey and Ramey (1995), Gilchrist, Sim, and Zakrajsek (2010), Basu and Bundick (2012), and Fernandez-Villaverde, Guerrón-Quintana, Rubio-Ramirez, and 
Uribe (2011) to name a few. Other papers, such as Gilchrist and Williams (2005), Jones, Manuelli, Siu, and Stacchetti (2005), Malkhozov and Shamloo (2010), and Kung and Schmid (2010), feature alternative channels for generating positive relationship between uncertainty and investment, and thus growth. In addition, Croce, Nguyen, and Schmid (2012), and Pastor and Veronesi (2012) highlight the negative impact of government policy uncertainty on prices and growth.

In terms of asset prices, Bansal and Yaron (2004) show that with Epstein and Zin (1989) recursive preferences, and an IES larger than one, economic uncertainty is a priced risk, and is negatively related to price-dividend ratios. More recently, Bansal, Kiku, Shaliastovich, and Yaron (2013) examine the implications of macroeconomic volatility for the time variation in risk premia, for the return on human capital, and for the cross-section of returns within a dynamic CAPM framework for which one of the factors, in addition to the standard cash flow and discount rate risks, is aggregate volatility. Campbell, Giglio, Polk, and Turley (2012) also analyze the role of uncertainty in an extended version of the ICAPM. While both papers document a significant role for uncertainty, Bansal et al. (2013) find both the betas and market price of uncertainty risk to be negative, and thus uncertainty to positively contribute to equity risk premia, whereas the evidence in Campbell et al. (2012) is more mixed in terms of whether assets have negative or positive exposure (beta) to volatility. The empirical framework in this paper, allowing for two types of uncertainties, can in principle accommodate several of these uncertainty effects.

In terms of analyzing two types of uncertainties, the literature has mainly focused on return-based uncertainty measures. Patton and Sheppard (2011) and Feunou, Jahan-Parvar, and Tédongap (2013) use return-based semivariance measures for capturing good and bad volatility. Specifically, in the context of stock returns downside risk, Feunou et al. (2013) study the effects of good and bad volatility on equity returns, measured by the positive and negative semivariances of returns in a similar fashion to our approach. They construct the volatilities from market data and focus on the implication for return moments, whereas our focus is on devising bad and good uncertainty measures from macro aggregates. In terms of utilizing macro aggregates, Bekaert and Engstrom (2009) analyze a habit model with bad and good environments in consumption growth, and show how such an extended model helps in accounting for aggregate asset prices. Our theoretical analysis is cast within a recursive preference framework which focuses on distinct shocks to good and bad uncertainty, yet allows 
for an important and separate feedback effect from uncertainty to growth. This is motivated by our novel empirical findings on the differential impact of good and bad uncertainty on growth of macroeconomic variables, as well as asset prices.

The rest of this paper is organized as follows. In Section 2 we provide a theoretical framework for good and bad uncertainty and highlight their role for future growth and asset prices. Section 3 discusses our empirical approach to construct good and bad uncertainty in the macroeconomic data. In Section 4 we show our empirical results for the effect of good bad uncertainties on aggregate macro quantities and aggregate asset prices, and the role of uncertainty risks for the market return and the cross-section of risk premia. Section 5 discusses the robustness of our key empirical results, and the last Section provides concluding comments.

\section{Economic Model}

To provide an economic structure for our empirical analysis, in this section we lay out a version of the long-run risks model that incorporates fluctuations in good and bad macroeconomic uncertainties. We use our economic model to highlight the roles of the good and bad uncertainties for the future growth and the equilibrium asset prices.

\section{$2.1 \quad$ Preferences}

We consider a discrete-time endowment economy. The preferences of the representative agent over the future consumption stream are characterized by the Kreps and Porteus (1978) recursive utility of Epstein and Zin (1989) and Weil (1989):

$$
U_{t}=\left[(1-\beta) C_{t}^{\frac{1-\gamma}{\theta}}+\beta\left(E_{t} U_{t+1}^{1-\gamma}\right)^{\frac{1}{\theta}}\right]^{\frac{\theta}{1-\gamma}},
$$

where $C_{t}$ is consumption, $\beta$ is the subjective discount factor, $\gamma$ is the risk-aversion coefficient, and $\psi$ is the elasticity of intertemporal substitution (IES). For ease of notation, the parameter $\theta$ is defined as $\theta \equiv \frac{1-\gamma}{1-\frac{1}{\psi}}$. Note that when $\theta=1$, that is, $\gamma=$ $1 / \psi$, the recursive preferences collapse to the standard case of expected power utility, in which case the agent is indifferent to the timing of the resolution of uncertainty of 
the consumption path. When risk aversion exceeds the reciprocal of IES $(\gamma>1 / \psi)$, the agent prefers early resolution of uncertainty of consumption path, otherwise, the agent has a preference for late resolution of uncertainty.

As is shown in Epstein and Zin (1989), the logarithm of the intertemporal marginal rate of substitution implied by these preferences is given by:

$$
m_{t+1}=\theta \log \beta-\frac{\theta}{\psi} \Delta c_{t+1}+(\theta-1) r_{c, t+1},
$$

where $\Delta c_{t+1}=\log \left(C_{t+1} / C_{t}\right)$ is the log growth rate of aggregate consumption, and $r_{c, t}$ is a log return on the asset which delivers aggregate consumption as dividends (the wealth portfolio). This return is different from the observed return on the market portfolio as the levels of market dividends and consumption are not the same. We solve for the endogenous wealth return and the equilibrium stochastic discount factor in 2.2 using the dynamics for the endowment process and the standard Euler equation,

$$
E_{t}\left[\exp \left\{m_{t+1}\right\} R_{i, t+1}\right]=1
$$

which hold for the return on any asset in the economy, $R_{i, t+1}$, including the wealth portfolio.

\subsection{Consumption Dynamics}

Our specification of the endowment dynamics incorporates the underlying channels of the long-run risks model of Bansal and Yaron (2004), such as the persistent fluctuations in expected growth and the volatility of consumption process. The novel ingredients of our model include: (i) the decomposition of the total macroeconomic volatility into good and bad components which separately affect good and bad consumption shocks, and (ii) the direct effect of macroeconomic volatilities on future economic growth. We show that these new model features are well-motivated empirically and help us interpret the relation between the good and bad uncertainties, the economic growth, and the asset prices in the data. 
Specifically, our benchmark specification for the consumption dynamics can be written as follows:

$$
\begin{aligned}
\Delta c_{t+1} & =\mu_{c}+x_{t}+\sigma_{c}\left(\varepsilon_{g, t+1}-\varepsilon_{b, t+1}\right), \\
x_{t+1} & =\rho x_{t}+\tau_{g} V_{g t}-\tau_{b} V_{b t}+\sigma_{x}\left(\varepsilon_{g, t+1}-\varepsilon_{b, t+1}\right),
\end{aligned}
$$

where $x_{t}$ is the predictable component of consumption growth, and $\varepsilon_{g t+1}$ and $\varepsilon_{b t+1}$ are two mean-zero consumption shocks which for parsimony affect both the realized and expected consumption growth.4 Similar to Bekaert and Engstrom (2009), for analytical convenience we model each consumption shock as a demeaned Gamma innovation with a normalized scale parameter of 1 and a time-varying shape parameter, denoted by $V_{g t}$ for $\varepsilon_{g t+1}$ and $V_{b t}$ for $\varepsilon_{b t+1}$ :

$$
\varepsilon_{i, t+1}=\tilde{\varepsilon}_{i, t+1}-V_{i t}, \quad \tilde{\varepsilon}_{i t+1} \sim \Gamma\left(V_{i t}, 1\right), \quad \text { for } i=\{g, b\}
$$

Because Gamma shocks have only positive support, $\varepsilon_{g t}$ and $\varepsilon_{b t}$ separately capture positive and negative consumption innovations. Due to the distributional assumption, their volatilities are time-varying and driven by the shape parameters $V_{g t}$ and $V_{b t}$; in particular,

$$
\operatorname{Var}_{t} \varepsilon_{g, t+1} \equiv V_{g t}, \quad \operatorname{Var}_{t} \varepsilon_{b, t+1} \equiv V_{b t}
$$

This allows us to interpret $V_{g t}$ and $V_{b t}$ as good and bad macroeconomic uncertainties, that is, uncertainties regarding the right and left tail movements in consumption growth, respectively. The total consumption uncertainty is equal to the sum of the good and bad uncertainties, $V_{g t}+V_{b t}$. Note that in this formulation higher order moments, such as skewness and kurtosis, are also time varying and are driven by $V_{g t}$ and $V_{b t} !^{5}$

\footnotetext{
${ }^{4}$ It is straightforward to extend the specification to allow for separate shocks in realized and expected consumption growth rates and break the perfect correlation of the two. This does not affect our key results, and so we do not entertain this case to ease the exposition

${ }^{5}$ There are alternative ways to introduce time-varying higher-order moments of cashflow fundamentals, such as consumption and dividends (see e.g., Eraker and Shaliastovich (2008), Drechsler and Yaron (2011), Colacito, Ghysels, and Meng (2013), and Wachter (2013)).
} 
In our specification, the good and bad uncertainties follow separate AR(1) processes,

$$
\begin{aligned}
& V_{g, t+1}=\left(1-\nu_{g}\right) V_{g 0}+\nu_{g} V_{g t}+\sigma_{w g} w_{g, t+1}, \\
& V_{b, t+1}=\left(1-\nu_{b}\right) V_{b 0}+\nu_{b} V_{b t}+\sigma_{w b} w_{b, t+1},
\end{aligned}
$$

where for $i=\{g, b\}, V_{i 0}$ is the level, $\nu_{i}$ the persistence, and $w_{i, t+1}$ the shock in the uncertainty. For simplicity, the volatility shocks are Normally distributed, and we let $\alpha$ denote the correlation between the two shocks.

By construction, the macro volatilities govern the magnitude of the good and bad consumption innovation. In addition to that, our feedback specification in (2.5) also allows for a direct effect of good and bad macro uncertainty on future levels of economic growth. Backus et al. (2010) use a similar feedback specification from a single (total) volatility to future growth. Our specification features two volatilities (good and bad) and for $\tau_{g}>0$ and $\tau_{b}>0$, an increase in good volatility raises future consumption growth rates, while an increase in bad volatility dampens future economic growth. The two-volatility specification captures the economic intuition that good uncertainty, through the positive impact of new innovation on growth opportunities, would increase investment and hence future economic growth, while bad uncertainty, due to the unknown magnitude of adverse news and its impact on investment, would result in lower growth in the future. While we do not provide the primitive micro-foundation for this channel, we show direct empirical evidence to support our volatility feedback for the macroeconomic growth rates. Further, we show that the volatility feedback for future cash flows also leads to testable implications for the asset prices which are supported in the data.

\subsection{Equilibrium Asset Prices}

We use a standard log-linearization approach to obtain analytical solutions to our equilibrium model. Below we show a summary of our key results, and all the additional details are provided in Appendix A. 
In equilibrium, the solution to the log price-consumption ratio on the wealth portfolio is linear in the expected growth and the good and bad uncertainty states:

$$
p c_{t}=A_{0}+A_{x} x_{t}+A_{g v} V_{g t}+A_{b v} V_{b t} .
$$

The slope coefficients are given by:

$$
\begin{aligned}
A_{x} & =\frac{1-\frac{1}{\psi}}{1-\kappa_{1} \rho} \\
A_{g v} & =\tilde{A}_{g v}+\tau_{g} \frac{\kappa_{1} A_{x}}{1-\kappa_{1} \nu_{g}}, \quad \tilde{A}_{g v}=\frac{f\left(\theta\left(\left(1-\frac{1}{\psi}\right) \sigma_{c}+\kappa_{1} A_{x} \sigma_{x}\right)\right)}{\theta\left(1-\kappa_{1} \nu_{g}\right)} \\
A_{b v} & =\tilde{A}_{b v}-\tau_{b} \frac{\kappa_{1} A_{x}}{1-\kappa_{1} \nu_{b}}, \quad \tilde{A}_{b v}=\frac{f\left(-\theta\left(\left(1-\frac{1}{\psi}\right) \sigma_{c}+\kappa_{1} A_{x} \sigma_{x}\right)\right)}{\theta\left(1-\kappa_{1} \nu_{g}\right)}
\end{aligned}
$$

where the $\tilde{A}$ s are the uncertainty loadings on the price consumption ratio that would be obtained if the consumption dynamics did not include a direct feedback from uncertainty to growth prospects, namely if $\tau_{b}=\tau_{g}=0$. The parameter $\kappa_{1} \in(0,1)$ is the log-linearization coefficient, and the function $f(u)$ captures the shape of the moment-generating function of the underlying consumption shocks:

$$
\log E_{t} e^{u \varepsilon_{i, t+1}}=f(u) V_{i, t}, \quad \text { for } i=\{g, b\}
$$

For Gamma distribution, the function $f(u)$ is given by $f(u)=-(\log (1-u)+u)$. Note that $f($.$) is non-negative, and is asymmetric due to the positive skewness of Gamma$ distribution: $f(u)>f(-u)$ for $u>0$.

As can be seen from the above equations, the response of the asset valuations to the underlying macroeconomic states is pinned down by the preference parameters and model parameters which govern the consumption dynamics. The solution to the expected growth loading $A_{x}$ is identical to Bansal and Yaron (2004), and implies that when the substitution effect dominates the wealth effect $(\psi>1)$, asset prices rise with positive growth prospects: $A_{x}>0$.

The expressions for the uncertainty loadings are more general than the ones in the literature and reflect our assumptions on the volatility dynamics. First, our specification separates positive and negative consumption innovations which have their own good and bad volatilities, respectively. The impact of this pure volatility channel on asset prices is captured by the first components of the volatility loadings in 2.10 , 
$\tilde{A}_{g v}$ and $\tilde{A}_{b v}$. In particular, when both $\gamma$ and $\psi$ are above one, these two loadings are negative: $\tilde{A}_{g v}, \tilde{A}_{b v}<0$. That is, with a strong preference for early resolution of uncertainty, the agent dislikes volatility, good or bad, so the direct effect of an increase in uncertainty about either positive or negative tail of consumption dynamics is to decrease equilibrium equity prices. In the absence of cash flow effect, both good and bad uncertainties depress asset valuations, albeit by a different amount. Indeed, due to a positive skewness of Gamma distribution, an increase in good (bad) uncertainty asymmetrically raises the right (left) tail of the future consumption growth distribution, and this asymmetry leads to a quantitatively larger negative response of the asset prices to bad uncertainty than to good uncertainty: $\left|\tilde{A}_{b v}\right|>\left|\tilde{A}_{g v}\right|$.

In addition to the direct volatility effect, in our model the good and bad uncertainties can also impact asset prices through their feedback on future cash flows (see equation 2.5). For $\tau_{b}>0$, the negative effect of bad uncertainty on future expected growth further dampens asset valuations, and as shown in 2.10$)$, the bad volatility coefficient $A_{b v}$ becomes even more negative. On the other hand, when good uncertainty has a positive and large enough impact on future growth, the cash flow effect of the good uncertainty can exceed its direct volatility effect, and as a result the total asset-price response to good uncertainty can become positive: $A_{g v}>0$. Hence, in our framework, good and bad uncertainties can have opposite impact on equity prices, with bad uncertainty shocks decreasing and good uncertainty shocks increasing asset valuations, which we show is an important aspect of the economic data.6

In the model, the good and bad uncertainty can also have different implications on equilibrium risk-free rates. Using a standard Euler equation (2.3), the solutions to equilibrium yields on $n$-period real bonds are given by the linear functions in the underlying state variables:

$$
y_{t, n}=\frac{1}{n}\left(B_{0, n}+B_{x, n} x_{t}+B_{g v, n} V_{g t}+B_{b v, n} V_{b t}\right),
$$

where $B_{x, n}, B_{g v, n}$ and $B_{b v, n}$ are the bond loadings to expected growth, good, and bad uncertainty factors, whose solutions are provided in the Appendix. As shown in the literature, real bond yields increase at times of high expected growth, and the bond

\footnotetext{
${ }^{6}$ Note that in our simple endowment economy, welfare is increasing in the value of the consumption claim. When $A_{g v}$ is positive, the implication is that good uncertainty shock increases welfare. This is not surprising since for $A_{g v}$ to be positive there must be a significant positive feedback from this uncertainty to future growth. The bad uncertainty, as in Bansal and Yaron (2004), unambiguously reduces welfare.
} 
loading $B_{x, n}$ is positive. Further, an increase in either good and bad uncertainty raises the precautionary savings motive for the representative agent, so the direct impact of either uncertainty on risk-free rates is negative. However, in addition to the direct volatility effect, in our framework good and bad uncertainties also have an impact on future economic growth. Bad uncertainty reduces future growth rates which further dampens interest rates, so $B_{b v, n}$ becomes more negative. On the other hand, the positive cash flow impact of good volatility can counteract the precautionary savings motive at longer maturities and can lead to a positive response of interest rates to good uncertainty. Thus, due to the volatility feedback, in our framework good and bad uncertainties can have opposite effect on the risk-free rates, which we show is consistent with the data.

\subsection{Risk Compensation}

Using the model solution to the price-consumption ratio in 2.9 , we can provide the equilibrium solution to the stochastic discount factor in terms of the fundamental states and the model and preference parameters. The innovation in the stochastic discount factor, which characterizes the sources and magnitudes of the underlying risk in the economy, is given by:

$$
m_{t+1}-E_{t}\left[m_{t+1}\right]=-\lambda_{x} \sigma_{x}\left(\varepsilon_{g, t+1}-\varepsilon_{b, t+1}\right)-\lambda_{g v} \sigma_{g w} w_{g, t+1}-\lambda_{b v} \sigma_{b w} w_{b, t+1},
$$

and $\lambda_{x}, \lambda_{g v}$ and $\lambda_{b v}$ are the market-prices of risk of growth, good volatility, and bad volatility risks. Their solutions are given by:

$$
\begin{aligned}
\lambda_{x} & =(1-\theta) \kappa_{1} A_{x}+\gamma \frac{\sigma_{c}}{\sigma_{x}} \\
\lambda_{g v} & =(1-\theta) \kappa_{1} A_{g v}, \\
\lambda_{b v} & =(1-\theta) \kappa_{1} A_{b v} .
\end{aligned}
$$

When the agent has a preference for early resolution of uncertainty, the market price of consumption growth risk $\lambda_{x}$ is positive: $\lambda_{x}>0$. Consistent with our discussion of the price-consumption coefficients, the market prices of the volatility risks depend on the strength of the volatility feedback for future cash flow. When the good and bad uncertainties have no impact on future growth $\left(\tau_{g}=\tau_{b}=0\right)$, the market prices 
of both volatility risks are negative. Indeed, with preference for early resolution of uncertainty, the agent dislikes volatility, good or bad, and thus high uncertainties represent high risk states for the investor. The market prices of uncertainty risks change when we introduce volatility feedback for future growth. When bad volatility predicts lower future growth, it makes bad volatility fluctuations even riskier, which increase, in absolute value, the market price of bad uncertainty risk, so $\lambda_{b v}<0$. On the other hand, when good uncertainty impacts positively future economic growth, the market price of good uncertainty can become positive: $\lambda_{g v}>0$. Thus, in our framework, bad and good uncertainty can have opposite market prices of risk.

To derive the implications for the risk premium, we consider an equity claim whose dividends represent a levered claim on total consumption, similar to Abel (1990) and Bansal and Yaron (2004). Specifically, we model the dividend growth dynamics as follows,

$$
\Delta d_{t+1}=\mu_{d}+\phi_{x} x_{t}+\sigma_{d} u_{d, t+1}
$$

where $\phi_{x}>0$ is the dividend leverage parameter which captures the exposure of equity cash flows to expected consumption risks, and $u_{d, t+1}$ is a Normal dividend-specific shock which for simplicity is homoscedastic and independent from other economic innovations.7 Using the dividend dynamics, we solve for the equilibrium return on the equity claim, $r_{d, t+1}$, in an analogous way to the consumption asset.

In equilibrium, the risk compensation on equities depends on the exposure of the asset to the underlying sources of risk $\beta$, the market prices of risks $\lambda$, and the quantity of risk:

$$
\begin{aligned}
E_{t} r_{d, t+1}-y_{t, 1}+\frac{1}{2} V_{t} r_{d, t+1} & =-\operatorname{cov}_{t}\left(m_{t+1}, r_{d, t+1}\right) \\
& =\lambda_{x} \beta_{x} \sigma_{x}^{2}\left(V_{g t}+V_{b t}\right)+\lambda_{g v} \beta_{g v} \sigma_{g w}^{2}+\lambda_{b v} \beta_{b v} \sigma_{b w}^{2} \\
& +\alpha \sigma_{b w} \sigma_{g w}\left[\lambda_{g v} \beta_{b v}+\lambda_{b v} \beta_{g v}\right] .
\end{aligned}
$$

The equity betas reflect the response of the asset valuations to the underlying sources of risks. Similarly to the consumption asset, the equity betas to growth risks and

\footnotetext{
${ }^{7}$ It is straightforward to generalize the dividend dynamics to incorporate stochastic volatility of dividend shocks, correlation with consumption shocks, and the feedback effect of volatility to expected dividends (see e.g., Bansal, Kiku, and Yaron (2011), and Schorfheide, Song, and Yaron (2013)). As our focus is on aggregate macroeconomic uncertainty, these extensions do not affect our key results, and for simplicity are not entertained. However, it is worth noting that, by convexity, separate idiosyncratic dividend volatility can be positively related to equity prices (see e.g., Pastor and Veronesi (2006), Ai and Kiku (2012), and Johnson and Lee (2013)).
} 
good volatility risks are positive, while the equity beta to bad uncertainty risks is negative: $\beta_{x}>0, \beta_{g v}>0, \beta_{b v}<0$.

In our model, all three sources of risks contribute to the equity risk premia, and further, the direct contribution to the equity risk premium of each risk source is positive. Indeed, when $\gamma>1$ and $\psi>1$, the market price of each risk has the same sign as the equity exposure to that risk, so expected growth, good, and bad volatility risks receive positive risk compensation in equities. The last term in the decomposition captures the covariance between good and bad uncertainty risk, and is negative when the two uncertainties have positive correlation $\alpha$.

\section{Data and Uncertainty Measures}

\subsection{Data}

In our benchmark analysis we use annual data from 1930 to 2012. Consumption and output data come from the Bureau of Economic Analysis (BEA) NIPA tables. Consumption corresponds to the real per capita expenditures on non-durable goods and services and output is real per capita gross domestic product minus government consumption. Capital investment data are from the NIPA tables; R\&D investment is available at the National Science Foundation (NSF) for the 1953 to 2008 period, and the R\&D stock data are taken from the BEA Research and Development Satellite Account for the 1959 to 2007 period. We supplement the annual data on these macroeconomic measures with the monthly data on industrial production from the Federal Reserve Bank of St. Louis.

Our asset-price data include 3-month Treasury bill rate, and the stock price and dividend on the broad market portfolio from CRSP. Additionally, we collect data on equity portfolios sorted on key characteristics, such as book-to-market ratio and size, from the Fama-French Data Library, and obtain aggregate earnings data from Shiller's website. We adjust nominal short-term rate by the expected inflation to obtain a proxy for the real risk-free rate. To measure the default spread, we use the difference between the BAA and AAA corporate yields from the Federal Reserve Bank of St. Louis. 
The summary statistics for the key macroeconomic variables are shown in Panel A of Table 1. Over the 1930 to 2012 sample period the average consumption growth is $1.8 \%$ and its volatility is $2.2 \%$. The average growth rates in output, capital investment, market dividends, and earnings are similar to that in consumption, and it is larger for the R\&D investment (3.5\%) over the 1954 to 2008 period. As shown in the Table, many of the macroeconomic variables are quite volatile relative to consumption: the standard deviation of earnings growth is $26 \%$, of capital investment growth is almost $15 \%$, and of the market dividend growth is $11 \%$. Most of the macroeconomic series are quite persistent with an $\mathrm{AR}(1)$ coefficient of about 0.5.

Panel B of Table 1 shows the summary statistics for the key asset-price variables. The average real log market return of $5.8 \%$ exceeds the average real rate of $0.3 \%$, which implies an equity premium (in logs) of $5.5 \%$ over the sample. The market return is also quite volatile relative to the risk-free rate, with a standard deviation of almost $20 \%$ compared to $2.5 \%$ for the risk-free rate. The corporate yield on BAA firms is on average $1.2 \%$ above that for the AAA firms, and the default spread fluctuates significantly over time. The default spread, real risk-free rate, and the market pricedividend ratio are very persistent in the sample, and their $\operatorname{AR}(1)$ coefficients range from 0.72 to 0.88 .

\subsection{Measurement of Good and Bad Uncertainties}

To measure good and bad uncertainty in the data, we follow the approach in BarndorffNielsen et al. (2010) to decompose the usual realized variance into two components that separately capture positive and negative (hence, "good" and "bad") movements in the underlying variable, respectively. While we focus on the variation in the aggregate macroeconomic variables, Feunou et al. (2013), and Patton and Sheppard (2011) entertain similar type of semivariance measures in the context of stock market variation 8

Specifically, consider an aggregate macroeconomic variable $y$ (e.g., industrial production, earnings, consumption), and let $\Delta y$ stand for the demeaned growth rate in

${ }^{8}$ The use of semivariance in finance goes back to at least Markowitz (1959). More recent applications include Hogan and Warren (1974), Lewis (1990), as well as the downside market beta as in Ang, Chen, and Xing (2006) and Lettau, Maggiori, and Weber (2013). 
$y$. Then, we define the positive and negative realized semivariances, $R V_{p}$ and $R V_{n}$, as follows:

$$
\begin{aligned}
& R V_{p, t+1}=\sum_{i=1}^{N} \mathbb{I}\left(\Delta y_{t+\frac{i}{N}} \geq 0\right) \Delta y_{t+\frac{i}{N}}^{2}, \\
& R V_{n, t+1}=\sum_{i=1}^{N} \mathbb{I}\left(\Delta y_{t+\frac{i}{N}}<0\right) \Delta y_{t+\frac{i}{N}}^{2},
\end{aligned}
$$

where $\mathbb{I}($.$) is the indicator function and N$ represents the number of observations of $y$ available during one period (a year in our case). It is worth noting that $R V(p)$ and $R V(n)$ add up to the standard realized variance measure, $R V$, that is,

$$
R V_{t+1}=\sum_{i=1}^{N} \Delta y_{t+\frac{i}{N}}^{2}=R V_{n, t+1}+R V_{p, t+1}
$$

Barndorff-Nielsen et al. (2010) show that in the limit the positive (negative) semivariance captures one-half of the variation of any Gaussian symmetric shifts in $\Delta y$, plus the variation of non-Gaussian positive (negative) fluctuations. ${ }^{9}$ Notably, the result in this paper implies that asymptotically, the semivariances are unaffected by movements in the conditional mean. Given finite-sample considerations, in Section 5 we construct semivariances after removing the conditional mean, and show that our results are robust to this change. In sum, the positive and negative semivariances are informative about the realized variation associated with movements in the right and left tail, respectively, of the underlying variable. Positive (negative) semivariance therefore corresponds to good (bad) states of the underlying variable and thus we use

${ }^{9}$ Formally, consider a general jump-diffusion process for $y_{t}$ :

$$
y_{t}=\int_{0}^{t} \mu_{s} d s+\int_{0}^{t} \sigma_{s} d W_{s}+J_{t}
$$

Then, when $N \rightarrow \infty$,

$$
\begin{aligned}
& R V_{p, t+1} \stackrel{p}{\rightarrow} \frac{1}{2} \int_{t}^{t+1} \sigma_{s}^{2} d s+\sum_{t \leq s \leq t+1} \mathbb{I}\left(\Delta J_{s} \geq 0\right) \Delta J_{s}^{2}, \\
& R V_{n, t+1} \stackrel{p}{\rightarrow} \frac{1}{2} \int_{t}^{t+1} \sigma_{s}^{2} d s+\sum_{t \leq s \leq t+1} \mathbb{I}\left(\Delta J_{s}<0\right) \Delta J_{s}^{2},
\end{aligned}
$$

for $\Delta J_{s}=y_{s}-y_{s^{-}}$. 
the predictable component of this measure as the empirical proxy for ex-ante good (bad) uncertainty.

To construct the ex-ante good and bad uncertainty measures from the realized semivariances, we project the logarithm of the future average $h$-period realized semivariance on the set of time $t$ predictors $X_{t}$ :

$$
\log \left(\frac{1}{h} \sum_{i=1}^{h} R V_{j, t+i}\right)=\text { const }_{j}+\nu_{j}^{\prime} X_{t}+\text { error }, \quad j=\{p, n\}
$$

and take as the proxies for the ex-ante good and bad uncertainty $V_{g}$ and $V_{b}$ the exponentiated fitted values of the projection above:

$$
V_{g, t}=\exp \left(\operatorname{const}_{p}+\nu_{p}^{\prime} X_{t}\right), \quad V_{b, t}=\exp \left(\operatorname{const}_{n}+\nu_{n}^{\prime} X_{t}\right)
$$

The log transformation ensures that our ex-ante uncertainty measures remain strictly positive.

In addition to measuring ex-ante uncertainties, we use a similar approach to construct a proxy for the expected consumption growth rate, $x_{t}$ which corresponds to the fitted value of the projection of future consumption growth on the same predictor vector $X_{t}$ :

$$
\begin{aligned}
\frac{1}{h} \sum_{i=1}^{h} \Delta c_{j, t+i} & =\text { const }_{c}+\nu_{c}^{\prime} X_{t}+\text { error }, \\
x_{t} & =\text { const }_{c}+\nu_{c}^{\prime} X_{t} .
\end{aligned}
$$

In our empirical applications we let $y$ be industrial production, which is available at monthly frequency, and use that to construct realized variance at the annual frequency. As there are twelve observations of industrial production within a year, our measurement approach is consistent with the model setup which allows for multiple good and bad shocks within a period (a year). To reduce measurement noise in constructing the uncertainties, in our benchmark empirical implementation we set the forecast window $h$ to three years. Finally, the set of the benchmark predictors $X_{t}$ includes positive and negative realized semivariances $R V_{p}, R V_{n}$, consumption growth 
$\Delta c$, the real-market return $r_{d}$, the market price-dividend ratio $p d$, the real risk-free rate $r_{f}$, and the default spread def ${ }^{10}$

Panel $\mathrm{C}$ of Table 1 reports the key summary statistics for our realized variance measures. The positive and negative semivariances contribute about equally to the level of the total variation in the economic series, and the positive semivariance is more volatile than the negative one. The realized variation measures co-move strongly together: the contemporaneous correlation between total and negative realized variances is $80 \%$, and the correlation between the positive and negative realized variance measures is economically significant, and amounts to $40 \%$.

Figure 1 shows the plot of the total realized variance, smoothed over the 3-year window to reduce measurement noise. As can be seen from the graph, the overall macroeconomic volatility gradually declines over time, consistent with the evidence in McConnell and Perez-Quiros (2000) and Stock and Watson (2002), as well as Bansal et al. (2005b), Lettau, Ludvigson, and Wachter (2008), and Bansal et al. (2013). Further, the realized variance is strongly counter-cyclical: indeed, its average value in recessions is twice as large as in expansions. The most prominent increases in the realized variance occur in the recessions of the early and late 1930s, the recession in 1945, and more recently in the Great Recession in the late 2000. Not surprisingly, the counter-cyclicality of the total variance is driven mostly by the negative component of the realized variance. To highlight the difference between the positive and negative variances, we show in Figure 2 the residual positive variance (smoothed over the 3 -year window) which is orthogonal to the negative variance. This residual is computed from the projection of the positive realized variance onto the negative one. As shown on the graph, the residual positive variance sharply declines in recessions, and the largest post-war drop in the residual positive variance occurs in the recession of 2008-2009.

We project the logarithms of the future 3-year realized variances and future 3-year consumption growth rates on the benchmark predictor variables to construct the exante uncertainty and expected growth measures. It is hard to interpret individual slope coefficients due to the correlation among the predictive variables, so for brevity we do not report them in the paper; typically, the market variables, such as the market price-dividend ratio, the market return, the risk-free rate, and the default spread, are

\footnotetext{
${ }^{10}$ As shown in Section 5, our results are robust to using standard OLS regression instead of the $\log$, the use of alternative predictors, different forecast windows $h$, removing the conditional mean in constructing the semivariance measures, and using other measures for $y$.
} 
significant in the regression, in addition to the lags of the realized variance measures themselves. The $R^{2}$ in these predictive regressions ranges from $30 \%$ for the negative variance and consumption growth to $60 \%$ for the positive variance.

We show the fitted values from these projections alongside the realized variance measures on Figure 3. The logs of the realized variances are much smoother than the realized variances themselves (see Figure 1), and the fitted values track well both the persistent declines and the business-cycle movements in the underlying uncertainty. We exponentiate the fitted values to obtain the proxies for the good and bad ex-ante uncertainties. Figures 4 and 5 show the total uncertainty and the residual ex-ante good uncertainty which is obtained from the projection of the good uncertainty on the bad uncertainty. Consistent with our discussion for the realized quantities, the total uncertainty gradually decreases over time, and the residual good uncertainty generally goes down in bad times. Indeed, in the recent period, the residual good uncertainty increases in the 1990s, and then sharply declines in the 2008. Notably, the ex-ante uncertainties are much more persistent than the realized ones: the $\mathrm{AR}(1)$ coefficients for good and bad uncertainties are about 0.5 , relative to $0.2-0.3$ for the realized variances.

\section{Empirical Results}

In this section we empirically analyze the implications of good and bad uncertainty along several key dimensions. In Section 4.1 we analyze the effects of uncertainty on aggregate macro quantities such as output, consumption, and investment. In Section 4.2 we consider the impact of uncertainties on aggregate asset prices such as the market price-dividend ratio, the risk free rate and the default spread. In Section 4.3 we examine the role of uncertainty for the market and cross-section of risk premia. Our benchmark analysis is based on the full sample from 1930-2012 and in the robustness section we show that the key results are maintained for the postwar period. 


\subsection{Macroeconomic Uncertainties and Growth}

Using our empirical proxies for good and bad uncertainty, $V_{g t}$ and $V_{b t}$, we show empirical support that good uncertainty is associated with an increase in future output growth, consumption growth, and investment, while bad uncertainty is associated with lower growth rates for these macro quantities. This is consistent with our cash flow dynamics in the economic model specification shown in equation (2.5).

To document our predictability evidence, we regress future growth rate for horizon $h$ years on the current proxies for good and bad uncertainty and the expected growth - that is we regress

$$
\frac{1}{h} \sum_{j=1}^{h} \Delta y_{t+j}=a_{h}+b_{h}^{\prime}\left[x_{t}, V_{g t}, V_{b t}\right]+\text { error }
$$

for the key macroeconomic variables of interest $y$ and forecast horizons $h$ from 1 to 5 years. Table 2 reports the slope coefficients and the $R^{2}$ for the regressions of consumption growth, private GDP, corporate earnings, and market dividend growth, and Table 3 shows the evidence for capital investment and R\&D measures.

It is evident from these two tables that across the various macroeconomic growth rates and across all the horizons, the slope coefficient on good uncertainty is always positive. This is consistent with the underlying premise of the feedback channel of good uncertainty on macro growth rates. Further, except for the three-year horizon for earnings, all slope coefficients for bad uncertainty are negative, which implies, consistently with theory, that a rise in bad uncertainty would lead to a reduction in macro growth rates. Finally, in line with our economic model, the expected growth channel always has a positive effect on the macro growth rates as demonstrated by the positive slope coefficients across all predicted variables and horizons.

The slope coefficients for all three predictive variables are economically large and in many cases are also statistically significant. The expected growth (cash flow) channel is almost always significant while the significance of good and bad uncertainty varies across predicted variables and maturities, although they tend to be significant particularly for the investment series. Because, the uncertainty measures are quite correlated, the evaluation of individual significance is difficult to assess. Therefore, in the last column of these tables we report the p-value of a Wald test for the joint 
significance of good and bad uncertainty. For the most part the tests reject the joint hypothesis that the loadings on good and bad uncertainty are zero. In particular, at the five-year horizon all of the p-values are below five percent, and they are below $1 \%$ for all the investment series at all the horizons.

It is worth noting that the adjusted $R^{2}$ s for predicting most of the future aggregate growth series are quite substantial. For example, the consumption growth $R^{2}$ is $50 \%$ at the one-year horizon, and the $R^{2}$ for the market dividends reaches $40 \%$, while it is about $10 \%$ for earnings and private GDP. For the investment and R\&D series the $R^{2}$ s at the one-year horizon are also substantial and range from $28 \%$ to $55 \%$. The $R^{2}$ s generally decline with the forecast horizon but for many variables, such as consumption and investment, they remain quite large even at five years.

To further illustrate the economic impact of uncertainty, Figures 6 - 8 provide impulse responses of key economic variables to good and bad uncertainty shocks. The impulse response functions are computed from a $\operatorname{VAR}(1)$ that includes bad uncertainty, good uncertainty, predictable consumption growth, and the macroeconomic variable of interest. Each figure provides three panels containing the responses to one standard deviation shock in good, bad, and total uncertainty, respectively.

Figure 6 provides the impulse response of private GDP growth to uncertainty. Panel A of the figure demonstrates that output growth increases by about $2.5 \%$ after one year due to a good uncertainty shock, and this positive effect persists over the next three years. Panel B shows that bad uncertainty decreases output growth by about $1.3 \%$ after one year, and remains negative even 10 years out. Panel $\mathrm{C}$ shows that output response to overall uncertainty mimics that of bad uncertainty but the magnitude of the response is significantly smaller - output growth is reduced by about $0.25 \%$ one year after the shock, and becomes positive after the second year. Recall that good and bad uncertainty have opposite effects on output yet they tend to comove and therefore the response to total uncertainty becomes less pronounced.

Figure 7 provides the impulse response of capital investment to bad, good, and total uncertainty, while Figure 8 shows the response of R\&D investment to these respective shocks. The evidence is even sharper than that for GDP. Both investment measures significantly increase with good uncertainty and remain positive till about five years out. These investment measures significantly decrease with a shock to bad uncertainty and total uncertainty, and become positive at about five year out. 
Total uncertainty is a muted version of the impulse response to bad uncertainty and is consistent with the finding in Bloom (2009) who shows a significant short-run reduction of total output in response to uncertainty shock, followed by a recovery and overshoot. Comparing Panels $\mathrm{B}$ and $\mathrm{C}$ of the figures highlights a potential bias in the magnitude of the decline in investment (and other macro quantities) in response to uncertainty when total uncertainty is used rather than bad uncertainty. For example for capital investment the maximal decline is about $2.3 \%$ for total uncertainty and $3 \%$ for bad uncertainty, and for the $\mathrm{R} \& \mathrm{D}$ investment the maximal response is $0.6 \%$ for total uncertainty while it is $1.1 \%$ for bad uncertainty, which indicates that the response differences are economically significant. Thus, decomposing uncertainty to good and bad components allows for a cleaner and sharper identification of the impact of uncertainty on growth.

Finally, we have also considered the impact of good and bad uncertainty on aggregate employment measures. Consistent with our findings for economic growth rates, we find that high good uncertainty predicts an increase in future aggregate employment and hours worked and a reduction in future unemployment rates, while an high bad uncertainty is associated with a decline in future employment and an increase in unemployment rates. In the interest of space, we do not report these results in the tables.

\subsection{Macroeconomic Uncertainties and Aggregate Prices}

We next use our good and bad uncertainty measures to provide empirical evidence that good uncertainty is associated with an increase in stock market valuations and decrease in the risk-free rates and the default spreads, while bad uncertainty has an opposite effect on these asset prices. This is consistent with the equilibrium asset-price implications in the model specification in Section 2 . 
To document the link between asset prices and uncertainties, we consider contemporaneous projections of the market variables on the expected growth and good and bad uncertainties, which we run both in levels and in first differences, that it 11 .

$$
\begin{aligned}
y_{t} & =a+b^{\prime}\left[x_{t}, V_{g t}, V_{b t}\right]+\text { error }, \\
\Delta y_{t} & =a+b^{\prime}\left[\Delta x_{t}, \Delta V_{g t}, \Delta V_{b t}\right]+\text { error } .
\end{aligned}
$$

where now $y$ refers to the dividend yield, risk free rate, or default spread.

Table 4 shows the slope coefficients and the $R^{2} \mathrm{~s}$ in these regressions for the market price-dividend ratio, the real risk-free rate, and the default spread. As is evident from the Table, the slope coefficients on bad uncertainty are negative for the market price-dividend ratio and the real risk-free rate, and they are positive for the default spread. The slope coefficients are of the opposite sign for the good uncertainty, and indicate that market valuations and interest rates go up and the default spread falls at times of high good uncertainty. Finally, the price-dividend ratio and the riskfree rates increase, while the default spread falls at times of high expected growth. Importantly, all these empirical findings are consistent with the implications of the model outlined in Section 2.

The slope coefficients for our three state variables are economically large and in most cases are also statistically significant individually; jointly, the two uncertainty variables are always significant with a $p$-value of $1 \%$ or below. The statistical significance is especially pronounced for the first-difference projections. Recall that the asset-price variables that we use are very persistent and may contain slow-moving near-unit root components which can impact statistical inference. First-difference (or alternatively, using the innovations into the variables) substantially reduces the autocorrelation of the series and allows us to more accurately measure the response of the asset prices to the underlying shocks in macroeconomic variables.

It is also worth noting that our three macroeconomic factors can explain a significant portion of the variation in asset prices. The $R^{2}$ in the regressions is $20 \%$ for the level of the price-dividend ratio and $60 \%$ for the first difference. For the real rate, the $R^{2}$ s are about $30 \%$, and it is $50 \%$ for the level of the default spread and $30 \%$ for the first difference.

\footnotetext{
${ }^{11}$ Instead of the first difference, we have also run the regression on the innovations into the variables, and the results are very similar.
} 
Figures 9 and 10 further illustrate the impact of uncertainties on asset prices and show the impulse responses of the price-dividend and price-earnings ratio to a one-standard deviation uncertainty shock from the VAR(1). Panel A of the Figure 9 documents that the price-dividend ratio increases by 0.07 one year after a good uncertainty shock and remains positive 10 years out. Similarly, the price-earnings ratio increases to about 0.04 in the first two years and its response is also positive at 10 years, as depicted in Panel A of Figure 10. Bad uncertainty shocks depress both immediate and future asset valuations. Price-dividend ratio drops by 0.06 on the impact, while price-earnings ratio declines by about 0.04 one year after, and all the impulse responses are negative 10 years after the shock. The response of the asset prices to the total uncertainty shock is significantly less pronounced than the response to bad uncertainty: the price-dividend ratio decreases immediately by only 0.04 on the impact of the total uncertainty shock, and the response reaches a positive level of 0.01 at 1 year and goes to zero after 3 years. Similarly, price-earnings ratio decreases by 0.01 one year after the impact, and the response becomes positive after 3 years. This weaker response of prices to total uncertainty is consistent with the analysis in Section 2, where it is shown that asset prices react less to good uncertainty than they do to bad uncertainty even when there was no feedback effect from good uncertainty to expected growth and asset prices reaction to both uncertainties were negative. In the model and in the data, total uncertainty is a combination of the correlated bad and good uncertainty components, which have opposite effect on the asset prices, and it therefore immediately follows that the response of asset prices to the total uncertainty shock is less pronounced. This muted response of asset prices to the total uncertainty masks the significant but opposite effects that different uncertainty components can have on asset valuations, and motivates our decomposition of the total uncertainty into the good and bad part.

\subsection{Macroeconomic Uncertainties and Cross-Section of Re- turns}

Using our empirical measures in the data, we show the implications of macroeconomic growth and good and bad uncertainties for the market and the cross-section of equity returns. Our empirical analysis yields the following key results. First, the risk exposures (betas) to bad uncertainty are negative and the risk exposures to good

uncertainty and expected growth are positive for the market and across most of the 
considered equity portfolios. This is consistent with our empirical evidence on the impact of growth and uncertainty fluctuations for the market valuations in Section 4.2, and with the equilibrium implications of the model in Section 2, Second, in line with the theoretical model, we document that bad uncertainty has a negative market price of risk, while the market prices of good uncertainty and expected growth risks are positive in the data. Hence, the high-risk states for the investors are those associated with low expected growth, low good uncertainty, and high bad uncertainty. We show that the equity risk premia for all the three macroeconomic risk factors are positive, and the uncertainty risk premia help explain the cross-section of expected returns beyond the cash flow channel.

Specifically, following our theoretical model, the portfolio risk premium is given by the product of the market prices of fundamental risks $\Lambda$, the variance-covariance matrix $\Omega$ which captures the quantity of risk, and the exposure of the assets to the underlying macroeconomic risk $\beta_{i}$ :

$$
E\left[R_{i, t+1}-R_{f, t}\right]=\Lambda^{\prime} \Omega \beta_{i}
$$

Given the innovations to the portfolio returns and to our aggregate risk factors, we can estimate the equity exposures and the market prices of expected growth and bad and good uncertainty risks using a standard Fama and MacBeth (1973) procedure. ${ }^{12}$ We first obtain the equity betas by running a multivariate regression of each portfolio return innovation on the innovations to the three factors:

$$
\begin{aligned}
r_{i, t+1}-E_{t} r_{i, t+1} & =\text { const }+\beta_{i, x}\left(x_{t+1}-E_{t}\left[x_{t+1}\right]\right)+\beta_{i, g v}\left(V_{g, t+1}-E_{t}\left[V_{g, t+1}\right]\right) \\
& +\beta_{i, b v}\left(V_{b, t+1}-E_{t}\left[V_{b, t+1}\right]\right)+\text { error. }
\end{aligned}
$$

The slope coefficients in the above projection, $\beta_{i, x}, \beta_{i, g v}$, and $\beta_{i, b v}$, represent the portfolio exposures to expected growth, good uncertainty, and bad uncertainty risk, respectively. Next we obtain the factor risk premia $\tilde{\Lambda}$ by running a cross-sectional regression of average returns on the estimated betas:

$$
E\left[R_{i, t+1}-R_{f, t}\right]=\tilde{\lambda}_{x} \beta_{i, x}+\tilde{\lambda}_{g v} \beta_{i, g v}+\tilde{\lambda}_{b v} \beta_{i, b v}+\text { error. }
$$

\footnotetext{
${ }^{12} \mathrm{We}$ have also considered an alternative econometric approach to measure return innovations similar to Bansal, Dittmar, and Lundblad (2005a), Hansen, Heaton, and Li (2008), and Bansal et al. (2013). The results are similar to our benchmark specification.
} 
We impose a zero-beta restriction in the estimation and thus run the regression without an intercept. The implied factor risk premia, $\tilde{\Lambda}=\left(\tilde{\lambda}_{x}, \tilde{\lambda}_{g v}, \tilde{\lambda}_{b v}\right)$, encompass both the vector of the underlying prices of risks $\Lambda$ and the quantity of risks $\Omega$ :

$$
\tilde{\Lambda}=\Omega \Lambda
$$

To calculate the underlying prices of expected growth, good and bad uncertainty risk $\Lambda$, we pre-multiply the factor risk premia $\tilde{\Lambda}$ by the inverse of the quantity of risk $\Omega$, which corresponds to the estimate of the unconditional variance of the factor innovation in the data.

In our benchmark implementation, we use the market return and the cross-section of 20 characteristic-sorted equity portfolios, such as ten portfolios sorted on the bookto-market ratio and ten portfolios sorted on size. Table 5 shows our key evidence concerning the estimated exposures of these portfolios to expected growth and uncertainty risks and the market prices of risks. Panel A of the Table documents that our macroeconomic risk factors are priced in the cross-section, and the market prices of expected growth and good uncertainty risk are positive, and that of bad uncertainty risk is negative. This indicates that the adverse economic states for the investor are those with low growth, high bad uncertainty, and low good uncertainty, consistent with the theoretical model. Panel B of the Table further shows that the equity returns are exposed to these three sources of risks. In particular, across all the assets, equities have a positive exposure to expected growth risk. The betas are nearly monotonically increasing from growth to value and from big to small stocks.

The equity exposures to bad uncertainty risks are negative for the market and for all the considered equity portfolios, while the equity betas to good uncertainty risks are all positive. Thus, our evidence indicates that equity returns increase at times of high expected growth and high good uncertainty and decrease at times of high bad uncertainty, and the magnitudes of the response vary in the cross-section.

The exposure of firms to good uncertainty risk along the book-to-market dimension is consistent with our earlier results regarding the interaction of uncertainties with investment growth. We showed a strong positive feedback effect from good uncertainty to future capital and R\&D investment growth rates. In unreported results, we find that the share of Value firms' investment in total private R\&D investment is roughly equal to that of Growth firms, for the period 1975-2012. For capital in- 
vestment, the share of Value firms' investment exceeds that of Growth firms. The dominance of Value firms' share in total investment implies that their investment behavior is strongly affected by good uncertainty.

We combine the estimated market prices of risk, quantity of risk, and the equity betas to evaluate the cross-sectional risk premia implications of our model, and report these empirical results in Table 6. As shown in the Table, our estimated model can match very well the level and the dispersion of the risk premia in the cross-section of assets. The market risk premium is $7.6 \%$ in the data relative to $7.7 \%$ in the model; the value spreads are $6.6 \%$ and $5.6 \%$ in the data and model, respectively, and the model-implied size spread is $7.4 \%$ relative to $8.9 \%$ in the data. We further use the risk premium condition (4.1) to provide the decomposition of the model risk premia into the various risk contributions. Because our risk factors are correlated, in addition to the own risk compensations for individual shocks (i.e., terms involving the variances on the diagonal of $\Omega$ ) we also include the risk components due to the interaction of different shocks (i.e., the covariance elements off the diagonal). As shown in the Table, the direct risk compensations for the expected growth and good and bad uncertainty shocks are positive for all portfolios. This is an immediate consequence of our empirical finding that the equity betas and the market prices of risks are of the same sign, so the direct contribution of each source of risk to the total equity risk premium is positive. On the other hand, the risk premia interaction terms can be negative and quite large, e.g. the risk premia due to covariance of good and bad uncertainty. While it is hard to assess separate risk contributions of each risk factor due to the non-negligible covariance interactions, our results suggest that both good and bad uncertainties have considerable impact on the level and the cross-section of returns.

Overall, our findings for the expected growth risk channel are in line with Bansal et al. (2005a), Hansen et al. (2008) and Bansal et al. (2013) who show the importance of growth risk for the cross-section of expected returns. Our evidence for the bad uncertainty is further consistent with Bansal et al. (2013), who document that total macroeconomic volatility has a negative market price of risk and depresses asset valuations in the cross-section. On the other hand, our finding for the separate role of the good uncertainty for the stock returns, above and beyond the expected growth and total uncertainty channel, is a novel contribution of this paper. 


\section{Robustness}

Our benchmark empirical results are based on the predictive uncertainty measures which are constructed from industrial production data, and which span the full sample period from 1930 to 2012. In this section, we show that our main conclusions are not mechanical and are robust to alternative proxies for the realized variation measures, the construction of the ex-ante uncertainties, and using the post-war period.

\subsection{Simulation Analysis}

We use a calibrated model to conduct a Monte-Carlo simulation analysis of the realized semivariances and verify that our empirical results are not driven by the mechanics of the constructed estimators. Specifically, we consider a long-run risks model of Bansal and Yaron (2004) which features conditionally Gaussian consumption shocks, a single stochastic volatility process, and no volatility feedback into the expected growth. Hence, under the null of the model, there are no separate movements in good and bad volatilities and no effect of volatility on future growth. This allows us to assess whether the mechanics of the construction of the semivariances can spuriously generate our empirical findings. The model setup and calibration are described in Appendix B and follow Bansal et al. (2011). We simulate the model on monthly frequency, and use the same approach as in Section 3.2 to construct realized positive and negative variances based on the simulated consumption data. The ex-ante expectations of the quantities are determined from the projections on the model predictive variables, which include positive and negative semivariances, consumption growth, market return, the market-price dividend ratio, and the risk-free rate.

Tables 7,8 show the model evidence for the projections of consumption and dividend growth rates, for horizons of 1 to 5 years, on the extracted expected growth, and the good and bad uncertainties. We report model evidence for finite samples of 83 years each, and population values based on a long simulation of 1,000,000 years. The top panels in the Tables report the findings under the benchmark specification. Consistent with our empirical robustness analysis (see below), we also consider two modifications of the benchmark specification, where the predictive uncertainties are based on straight OLS rather than log of the variances, and where we use the AR(1) 
fit to the monthly consumption growth to remove the fluctuations in the conditional mean.

Table 7 reports the slopes and the $R^{2}$ s from the consumption and dividend projections. As shown in the Table, the slope coefficients on bad (good) volatility are generally positive (negative), at least for the short horizons, and these coefficients decrease (increase) with the horizon of the regressions. The evidence is especially pronounced in the population; indeed, in benchmark model specification all the bad (good) volatility slopes from 1 to 5 years to maturity are positive (negative). This is opposite of what we find in the data, where the coefficients on bad (good) volatility are generally most negative (positive) at short horizons, and tend to increase (decrease) with the horizon. The Table also shows a considerable amount of noise in estimating the ex-ante uncertainties in small samples, as all the small-sample volatility loadings are insignificant.

In Table 8 we assess the joint probability for finding the same volatility signs as in the data combining the evidence across the horizons and across the consumption and dividend regressions. The Table documents that across 1 to 5 year horizon consumption growth regressions, all bad volatility loadings turn out negative and all good volatility turn out positive in $3 \%$ of the cases. For dividend regressions, this

number is $9 \%$. Finally, combining both the consumption and dividend predictability, the probabilities of finding the same signs as in the data are less than $1 \%$. Thus, the simulation evidence clearly shows that the patterns in volatility loadings we find in the data are not due to the mechanics of construction of the realized variance estimators.

\subsection{Empirical Analysis}

We consider various robustness checks concerning the construction of the realized variances in the data. For the first round of robustness check, we maintain the industrial production growth data to measure the realized variances and modify the construction of ex-ante good and bad uncertainties in several dimensions. First, to mitigate potential small-sample concerns with the realized variance estimators, we consider removing the conditional (rather than the unconditional) mean of industrial production growth in constructing good and bad realized variances. We do so by using the residuals based on fitting an $\mathrm{AR}(1)$ to industrial production growth. Key results 
for this specification are reported in Table 9, By large, the findings are qualitatively and quantitatively similar to those reported in the benchmark specification. It is worth emphasizing that asymptotically the conditional mean dynamics do not effect the properties of the realized variance. Our empirical results indicate the conditional mean dynamics also do not affect the realized variance in our finite sample.

Next, we consider changing the cutoff point for defining good and bad uncertainty. Instead of using the unconditional mean, now the good state is defined for states in which industrial production is above its 75 percentile. Table 10 provides key results for this case and shows that the main findings for our benchmark specification are intact. Further, instead of taking the logs of the realized variances and exponentiating the fitted values, we run standard OLS regressions on the levels of the positive and negative realized variances and use directly the fitted values from these regressions as proxies for good and bad uncertainties, respectively. Alternatively, while in our benchmark approach we predict the realized variances over a three-year forecast window, for robustness, we also consider shorter and longer horizons, such as one and five-year window specification. We also expand the set of the predictive variables and include the term spread, defined as the difference between the 10-year and 3-month Treasury yield, to the benchmark set of predictors. In the interest of space we do not report these additional tables but note that across all of these modifications of the benchmark specification, we confirm our key empirical results regarding: (i) the relation between good and bad uncertainties and the future macroeconomic growth rates, (ii) the relation between the two uncertainties and the aggregate asset prices, and (iii) the market prices and exposures to the three underlying risks.

For the second set of robustness checks, we consider monthly earnings data, instead of industrial production data, to construct realized variances. Table 11 shows a summary of the key macroeconomic and asset pricing implications of the good and bad uncertainty using these alternative measures of volatility. The Table shows that the earnings-based uncertainty measures deliver very similar implications to the industrial-production based ones. Indeed, as shown in Panel A, with a single exception of R\&D investment growth, all future macroeconomic growth rates increase following positive shocks to expected growth, positive shocks to good uncertainty, and negative shocks to bad uncertainty. As shown in Panel B of the Table, the contemporaneous responses of aggregate asset prices to uncertainty based on earnings volatility measures are very similar to those based on industrial production measures 
of volatility. With the exception of the risk-free rate projection, this evidence again is consistent with interpreting the high expected growth, high good uncertainty, and low bad uncertainty as good states for asset valuations. This conclusion is confirmed in Panel $\mathrm{C}$ which documents that the market prices of expected consumption and good uncertainty risks are positive, and that of bad uncertainty is negative. As in the benchmark specification, the estimated equity exposures to these risks factors have the same sign as the market prices of risks, so the direct contribution of each macroeconomic risk to the equity risk premium is positive.

Using the estimated expected growth and uncertainty measures we verify whether the results are robust to the post-war sample. Table 12 shows the results for the industrial-production based uncertainty measures, while Table 13 shows the evidence using the earnings-based uncertainty. For the majority of the considered projections, our benchmark conclusions for the relation of the macroeconomic growth rates and asset prices are unchanged.

\section{Conclusion}

In this paper we propose a novel framework and empirical measures for studying good and bad aggregate uncertainty. We define good and bad uncertainty as the variance associated with the respective positive and negative innovations of an underlying macroeconomic variable. We show that fluctuations in good and bad macroeconomic uncertainty oppositely and significantly impact future growth and asset valuations.

We develop a version of the Long Run Risk model which features separate volatilities for good and bad consumption shocks, and feedback from volatilities to future growth. We show equity prices decline with bad uncertainty and rise with good uncertainty, provided there is a sufficiently large feedback from good uncertainty to future growth. Moreover, we show that the market price of risk and equity beta are both positive for good uncertainty, while they are both negative for bad uncertainty. This implies that both good and bad uncertainty risks contribute positively to risk premia.

Empirically, we use semivariances based on industrial production to construct good and bad uncertainties, and show the model implications are consistent with the data. Specifically, future economic growth, such as consumption, dividend, earnings, GDP, and investment, rise with good uncertainty, while they fall with bad uncer- 
tainty. Consistent with the model, equity prices and interest rates increase (decrease) with good (bad) uncertainty. Finally, using the cross-section of assets we estimate a positive market price of good uncertainty risk, and a negative one for bad uncertainty risk. In all, our theoretical and empirical evidence shows the importance of separate movements of good and bad uncertainty for economic growth and asset prices. We leave it for future work to provide explicit economic channels, linking good and bad uncertainty risks with technological aspects of production, investment, and financing opportunities. 


\section{A Benchmark Model Solution}

The solution of the model relies on a standard log-linearization of returns,

$$
r_{c, t+1} \approx \kappa_{0}+\kappa_{1} p c_{t+1}-p c_{t}+\Delta c_{t+1}
$$

In equilibrium, the price-consumption ratio is linear in the expected growth and uncertainty factors, as shown by equation $(2.9)$. The log-linearization parameter $\kappa_{1}$ satisfies the equation,

$$
\begin{aligned}
\log \kappa_{1} & =\log \delta+\left(1-\frac{1}{\psi}\right) \mu_{c}+A_{g v}\left(1-\kappa_{1} \nu_{g}\right) V_{g 0}+A_{b v}\left(1-\kappa_{1} \nu_{b}\right) V_{b 0} \\
& +\theta \kappa_{1}^{2}\left[\frac{1}{2} A_{g v}^{2} \sigma_{g w}^{2}+\frac{1}{2} A_{b v}^{2} \sigma_{b w}^{2}+\alpha A_{g v} A_{b v} \sigma_{g w} \sigma_{b w}\right] .
\end{aligned}
$$

The real stochastic discount factor is equal to:

$$
\begin{aligned}
m_{t+1} & =m_{0}+m_{x} x_{t}+m_{g v} V_{g t}+m_{b v} V_{b t} \\
& -\lambda_{x} \sigma_{x}\left(\varepsilon_{g, t+1}-\varepsilon_{b, t+1}\right)-\lambda_{g v} \sigma_{g w} w_{g, t+1}-\lambda_{b v} \sigma_{b w} w_{b, t+1},
\end{aligned}
$$

where the market prices of risk are specified in equations $(2.14)-(2.16)$, and the loadings on the state variables are given by,

$$
\begin{aligned}
& m_{x}=-\gamma+(1-\theta)\left(1-\kappa_{1} \rho\right) A_{x}=-\frac{1}{\psi}, \\
& m_{g v}=(1-\theta)\left(A_{g v}\left(1-\kappa_{1} \nu_{g}\right)-\kappa_{1} A_{x} \tau_{g}\right)=\frac{1-\theta}{\theta} f\left(\theta\left(\left(1-\frac{1}{\psi}\right) \sigma_{c}+\kappa_{1} A_{x} \sigma_{x}\right)\right), \\
& m_{b v}=(1-\theta)\left(A_{b v}\left(1-\kappa_{1} \nu_{b}\right)+\kappa_{1} A_{x} \tau_{b}\right)=\frac{1-\theta}{\theta} f\left(\theta\left(-\left(1-\frac{1}{\psi}\right) \sigma_{c}-\kappa_{1} A_{x} \sigma_{x}\right)\right) .
\end{aligned}
$$

The bond loadings satisfy the recursive equations:

$$
\begin{aligned}
B_{x, n} & =\rho B_{x, n-1}-m_{x}, \\
B_{g v, n} & =\nu_{g} B_{g v, n-1}-m_{g v}-f\left(-\sigma_{x}\left(\lambda_{x}+B_{x, n-1}\right)\right)+\tau_{g} B_{x, n-1}, \\
B_{b v, n} & =\nu_{b} B_{b v, n-1}-m_{b v}-f\left(\sigma_{x}\left(\lambda_{x}+B_{x, n-1}\right)\right)-\tau_{b} B_{x, n-1},
\end{aligned}
$$

for $B_{x, 0}=B_{g v, 0}=B_{b v, 0}=0$. 
Similarly, the return of the divided-paying asset can be expressed by:

$$
r_{d, t+1} \approx \kappa_{0, d}+\kappa_{1, d} p d_{t+1}-p d_{t}+\Delta d_{t+1}
$$

where $\kappa_{0, d}$ and $\kappa_{1, d}$ are the log-linearization parameters, and $\kappa_{1, d}$ satisfies:

$$
\begin{aligned}
\log \kappa_{1, d} & =m_{0}+\mu_{d}+H_{g v}\left(1-\kappa_{1, d} \nu_{g}\right) V_{g 0}+H_{b v}\left(1-\kappa_{1, d} \nu_{b}\right) V_{b 0} \\
& +\kappa_{1, d}^{2}\left[\frac{1}{2} H_{g v}^{2} \sigma_{g w}^{2}+\frac{1}{2} H_{b v}^{2} \sigma_{b w}^{2}+\alpha H_{g v} H_{b v} \sigma_{g w} \sigma_{b w}\right] .
\end{aligned}
$$

The equity betas are given by,

$$
\beta_{x}=\kappa_{1, d} H_{x}, \beta_{g v}=\kappa_{1, d} H_{g v}, \text { and } \beta_{b v}=\kappa_{1, d} H_{b v},
$$

where $H_{x}, H_{g v}$ and $H_{b v}$ are the equilibrium loadings of the price-dividend ratio on predictable consumption growth, good uncertainty bad uncertainty $H_{b v}$, respectively, and are given by:

$$
\begin{aligned}
H_{x} & =\frac{\phi_{x}+m_{x}}{1-\kappa_{1, d} \rho}, \\
H_{g v} & =\frac{f\left(\kappa_{1, d} H_{x} \sigma_{x}-\lambda_{x} \sigma_{x}\right)+\kappa_{1, d} H_{x} \tau_{g}+m_{g v}}{1-\kappa_{1, d} \nu_{g}}, \\
H_{b v} & =\frac{f\left(-\kappa_{1, d} H_{x} \sigma_{x}+\lambda_{x} \sigma_{x}\right)-\kappa_{1, d} H_{x} \tau_{b}+m_{b v}}{1-\kappa_{1, d} \nu_{b}},
\end{aligned}
$$

\section{B Long-Run Risks Model Specification}

In a standard long-run risks model consumption dynamics satisfies

$$
\begin{aligned}
\Delta c_{t+1} & =\mu+x_{t}+\sigma_{t} \eta_{t+1}, \\
x_{t+1} & =\rho x_{t}+\varphi_{e} \sigma_{t} \epsilon_{t+1}, \\
\sigma_{t+1}^{2} & =\sigma_{c}^{2}+\nu\left(\sigma_{t}^{2}-\sigma_{c}^{2}\right)+\sigma_{w} w_{t+1}, \\
\Delta d_{t+1} & =\mu_{d}+\phi x_{t}+\pi \sigma_{t} \eta_{t+1}+\varphi_{d} \sigma_{t} u_{d, t+1} .
\end{aligned}
$$

where $\rho$ governs the persistence of expected consumption growth $x_{t}$, and $\nu$ determines the persistence of the conditional aggregate volatility $\sigma_{t}^{2} . \eta_{t}$ is a short-run consumption shock, $\epsilon_{t}$ is the shock to the expected consumption growth, and $w_{t+1}$ is the shock to the conditional volatility of consumption growth; for parsimony, these three shocks are assumed to be i.i.d 
Normal. The parameter configuration for consumption and dividend dynamics used in our model simulation is identical to Bansal et al. (2011), and is given in Table B1.

Table B1: Model Calibration

\begin{tabular}{|c|c|c|c|c|}
\hline \multirow[t]{2}{*}{ Preferences } & $\delta$ & $\gamma$ & $\psi$ & \\
\hline & 0.9987 & 10 & 2 & \\
\hline \multirow[t]{2}{*}{ Consumption } & $\mu$ & $\rho$ & $\varphi_{e}$ & \\
\hline & 0.0015 & 0.975 & 0.038 & \\
\hline \multirow[t]{2}{*}{ Volatility } & $\sigma_{g}$ & $\nu$ & $\sigma_{w}$ & \\
\hline & 0.0072 & 0.999 & $2.8 \mathrm{e}-06$ & \\
\hline \multirow[t]{2}{*}{ Dividend } & $\mu_{d}$ & $\phi$ & $\varphi_{d}$ & $\pi$ \\
\hline & 0.0015 & 2.5 & 5.96 & 2.6 \\
\hline
\end{tabular}

The Table shows the calibrated parameters of the long-run risks model, monthly frequency. 


\section{References}

Abel, A. B., (1990), Asset prices under habit formation and catching up with the Joneses, American Economic Review 80, 38-42.

Ai, H. and D. Kiku, (2012), Volatility risks and growth options, Working Paper, University of Minnesota.

Ang, A., J. Chen, and Y. Xing, (2006), Downside risk, Review of Financial Studies 19, 1191-1239.

Backus, D., B. Routledge, and S. Zin, (2010), The cyclical component of US asset returns, Working Paper, NYU.

Bansal, R., R. F. Dittmar, and C. T. Lundblad, (2005a), Consumption, dividends, and the cross section of equity returns, The Journal of Finance 60, 1639-1672.

Bansal, R., V. Khatchatrian, and A. Yaron, (2005b), Interpretable asset markets?, European Economic Review 49, 531-560.

Bansal, R., D. Kiku, I. Shaliastovich, and A. Yaron, (2013), Volatility, the macroeconomy, and asset prices, Forthcoming, Journal of Finance.

Bansal, R., D. Kiku, and A. Yaron, (2011), An empirical evaluation of the long-run risks model for asset prices, Critical Finance Review 1, 183-221.

Bansal, R. and A. Yaron, (2004), Risks for the long run: A potential resolution of asset pricing puzzles, The Journal of Finance 59, 1481-1509.

Barndorff-Nielsen, O., S. Kinnebrock, and N. Shephard, (2010), Measuring downside risk-realised semivariance, Working paper, Oxford-Man Institute, University of Oxford.

Basu, S. and B. Bundick, (2012), Uncertainty shocks in a model of effective demand, NBER Working Paper 18420.

Bekaert, G. and E. Engstrom, (2009), Asset return dynamics under bad environment good environment fundamentals, Working paper, Columbia University.

Bloom, N., (2009), The impact of uncertainty shocks, Econometrica 77, 623-685. 
Campbell, J., S. Giglio, C. Polk, and R. Turley, (2012), An intertemporal CAPM with stochastic volatility, Working paper, Harvard University.

Colacito, R., E. Ghysels, and J. Meng, (2013), Skewness in expected macro fundamentals and the predictability of equity returns: Evidence and theory, Working paper, University of North Carolina.

Croce, M., T. Nguyen, and L. Schmid, (2012), The market price of fiscal uncertainty, Journal of Monetary Economics 59, 401-416.

Drechsler, I. and A. Yaron, (2011), What's vol got to do with it, Review of Financial Studies 24, 1-45.

Epstein, L. and M. Schneider, (2010), Ambiguity and asset markets, Annual Reviews of Financial Economics 2, 315-334.

Epstein, L. and S. Zin, (1989), Substitution, risk aversion, and the temporal behavior of consumption and asset returns: A theoretical framework, Econometrica 57, 937-969.

Eraker, B. and I. Shaliastovich, (2008), An equilibrium guide to designing affine pricing models, Mathematical Finance 18, 519-543.

Fama, E. F. and J. D. MacBeth, (1973), Risk, return, and equilibrium: Empirical tests, The Journal of Political Economy 81, 607-636.

Fernandez-Villaverde, J., P. Guerrón-Quintana, J. F. Rubio-Ramirez, and M. Uribe, (2011), Risk matters: The real effects of volatility shocks, The American Economic Review 101, 2530-2561.

Feunou, B., M. R. Jahan-Parvar, and R. Tédongap, (2013), Modeling market downside volatility, Review of Finance 17, 443-481.

Gilchrist, S., J. Sim, and E. Zakrajsek, (2010), Uncertainty, financial frictions and investment dynamics, Working paper, Boston University.

Gilchrist, S. and J. C. Williams, (2005), Investment, capacity, and uncertainty: a putty-clay approach, Review of Economic Dynamics 8, 1-27.

Hansen, L. and T. Sargent, (2010), Fragile beliefs and the price of model uncertainty, Quantitative Economics 1, 129-162. 
Hansen, L. P., J. C. Heaton, and N. Li, (2008), Consumption strikes back? Measuring long-run risk, Journal of Political Economy 116, 260-302.

Hogan, W. W. and J. M. Warren, (1974), Toward the development of an equilibrium capital-market model based on semivariance, Journal of Financial and Quantitative Analysis 9, 1-11.

Johnson, T. and J. Lee, (2013), On the systematic volatility of unpriced earnings, Forthcoming in Journal of Financial Economics.

Jones, L., R. Manuelli, H. Siu, and E. Stacchetti, (2005), Fluctuations in convex models of endogenous growth i: Growth effects, Review of Economic Dynamics $8,780-804$.

Kandel, S. and R. F. Stambaugh, (1991), Asset returns and intertemporal preferences, Journal of Monetary Economics 27, 39-71.

Kreps, D. M. and E. L. Porteus, (1978), Temporal resolution of uncertainty and dynamic choice theory, Econometrica 46, 185-200.

Kung, H. and L. Schmid, (2010), Long-term volatility, growth and asset pricing, Working paper, Duke University.

Lettau, M., S. C. Ludvigson, and J. A. Wachter, (2008), The declining equity premium: What role does macroeconomic risk play?, Review of Financial Studies $21,1653-1687$.

Lettau, M., M. Maggiori, and M. Weber, (2013), Conditional risk premia in currency markets and other asset classes, Forthcoming in Journal of Financial Economics.

Lewis, A. L., (1990), Semivariance and the performance of portfolios with options, Financial Analysts Journal 67-76.

Malkhozov, A. and M. Shamloo, (2010), Asset prices in affine real business cycle models, IMF Working Papers 1-42.

Markowitz, H., (1959), Portfolio selection: efficient diversification of investments, Yale university press.

McConnell, M. M. and G. Perez-Quiros, (2000), Output fluctuations in the united states: What has changed since the early 1980's?, The American Economic Review 90, 1464-1476. 
Pastor, L. and P. Veronesi, (2006), Was there a NASDAQ bubble in the late 1990s?, Journal of Financial Economics 81, 61 -100.

Pastor, L. and P. Veronesi, (2009), Learning in financial markets, Annual Review of Financial Economics 1, 361-381.

Pastor, L. and P. Veronesi, (2012), Uncertainty about government policy and stock prices, The Journal of Finance 67, 1219-1264.

Patton, A. J. and K. Sheppard, (2011), Good volatility, bad volatility: Signed jumps and the persistence of volatility, Working Paper, Oxford-Man Institute, University of Oxford.

Ramey, G. and V. Ramey, (1995), Cross-country evidence on the link between volatility and growth, American Economic Review 85, 11381151.

Schorfheide, F., D. Song, and A. Yaron, (2013), Identifying long-run risks: A bayesian mixed-frequency approach, Working paper, University of Pennsylvania.

Stock, J. and M. Watson, (2002), Has the business cycle changed and why, in Gertler, M. and K. Rogoff, eds., NBER Macroeconomics Annual: 2002, MIT Press, Cambridge, MA.

Wachter, J., (2013), Can time-varying risk of rare disasters explain aggregate stock market volatility?, Journal of Finance 68, 987-1035.

Weil, P., (1989), The equity premium puzzle and the risk-free rate puzzle, Journal of Monetary Economics 24, 401-421. 


\section{Tables and Figures}

\section{Table 1: Data Summary Statistics}

\begin{tabular}{|c|c|c|c|}
\hline & Mean & Std. Dev. & $\overline{\mathrm{AR}(1)}$ \\
\hline \multicolumn{4}{|c|}{ Panel A: Macro Growth Rates } \\
\hline Consumption growth & 1.84 & 2.16 & 0.50 \\
\hline GDP growth & 2.04 & 12.91 & 0.41 \\
\hline Earnings growth & 1.77 & 26.11 & 0.01 \\
\hline Market dividend growth & 1.27 & 11.32 & 0.20 \\
\hline Capital investment growth & 1.75 & 14.80 & 0.42 \\
\hline R\&D investment growth & 3.51 & 4.69 & 0.18 \\
\hline \multicolumn{4}{|c|}{ Panel B: Asset Prices } \\
\hline Market return & 5.79 & 19.85 & -0.01 \\
\hline Market price-dividend ratio & 3.39 & 0.45 & 0.88 \\
\hline Real risk-free rate & 0.34 & 2.55 & 0.73 \\
\hline Default spread & 1.21 & 0.81 & 0.72 \\
\hline \multicolumn{4}{|c|}{ Panel C: Realized Volatility } \\
\hline$R V_{p}$ & 2.34 & 7.37 & 0.24 \\
\hline$R V_{n}$ & 2.27 & 5.68 & 0.29 \\
\hline$R V$ & 4.61 & 10.91 & 0.44 \\
\hline
\end{tabular}

The Table shows summary statistics for the macroeconomic variables (Panel A), aggregate asset prices (Panel B), and the realized variance measures (Panel C). Consumption, private GDP, as well as capital and R\&D investment series are real and per capita. Dividends, earnings, stock prices and returns are computed for a broad market portfolio. The real risk-free rate corresponds to a 3 -month Tbill rate minus expected inflation. Default spread is the difference between the yields on BAAand AAA-rated corporate bonds. The total realized variance, $R V$, is based on the sum of squared observations of demeaned monthly industrial production growth over 1-year, re-scaled to match the unconditional variance of consumption growth. The positive and negative realized semivariances, $R V_{p}$ and $R V_{n}$, decompose the total realized variance into the components pertaining to only positive and negative movements in industrial production growth, respectively. All growth rates and returns are in percentages, and the realized variances are multiplied by 10,000. Data on R\&D investment are annual from 1954 to 2008, and all the other data are annual from 1930 to 2012. 
Table 2: Macroeconomic Uncertainties and Aggregate Growth

\begin{tabular}{|c|c|c|c|c|c|}
\hline & $x$ & $V_{b}$ & $V_{g}$ & Adj $-R^{2}$ & p-value \\
\hline \multicolumn{6}{|c|}{ Consumption Growth: } \\
\hline \multirow[t]{2}{*}{ 1Y Ahead } & 1.98 & -64.76 & 12.97 & 0.51 & 0.25 \\
\hline & {$[4.98]$} & {$[-1.42]$} & {$[0.83]$} & & \\
\hline \multirow[t]{2}{*}{ 3Y Ahead } & 1.07 & -22.56 & 12.67 & 0.33 & 0.05 \\
\hline & {$[2.98]$} & {$[-0.68]$} & {$[1.21]$} & & \\
\hline \multirow[t]{2}{*}{$5 Y$ Ahead } & 0.46 & -2.20 & 6.81 & 0.18 & $<0.01$ \\
\hline & {$[2.93]$} & {$[-0.08]$} & {$[0.73]$} & & \\
\hline \multicolumn{6}{|c|}{ GDP Growth: } \\
\hline \multirow[t]{2}{*}{ 1Y Ahead } & 4.87 & -733.08 & 277.73 & 0.07 & 0.25 \\
\hline & {$[7.37]$} & {$[-1.62]$} & {$[1.44]$} & & \\
\hline \multirow[t]{2}{*}{ 3Y Ahead } & 2.53 & -410.36 & 180.07 & 0.04 & 0.28 \\
\hline & {$[2.13]$} & {$[-1.29]$} & {$[1.44]$} & & \\
\hline \multirow[t]{2}{*}{$5 Y$ Ahead } & 1.46 & -142.27 & 66.85 & 0.01 & 0.02 \\
\hline & {$[2.53]$} & {$[-1.72]$} & {$[2.51]$} & & \\
\hline \multicolumn{6}{|c|}{ Market Dividend Growth: } \\
\hline \multirow[t]{2}{*}{ 1Y Ahead } & 8.93 & -474.89 & 55.04 & 0.41 & $<0.01$ \\
\hline & {$[4.46]$} & {$[-2.41]$} & {$[0.84]$} & & \\
\hline \multirow[t]{2}{*}{ 3Y Ahead } & 2.89 & -107.83 & 60.23 & 0.08 & 0.16 \\
\hline & {$[1.45]$} & {$[-0.66]$} & {$[1.17]$} & & \\
\hline \multirow[t]{2}{*}{ 5Y Ahead } & 1.22 & -182.40 & 79.83 & 0.04 & 0.01 \\
\hline & {$[1.52]$} & {$[-2.02]$} & {$[2.67]$} & & \\
\hline \multicolumn{6}{|c|}{ Earnings Growth: } \\
\hline \multirow[t]{2}{*}{ 1Y Ahead } & 12.34 & -682.77 & 134.02 & 0.10 & $<0.01$ \\
\hline & {$[3.59]$} & {$[-1.29]$} & {$[0.66]$} & & \\
\hline \multirow[t]{2}{*}{ 3Y Ahead } & 0.78 & 60.55 & 21.86 & -0.02 & 0.46 \\
\hline & {$[0.28]$} & {$[0.19]$} & {$[0.19]$} & & \\
\hline \multirow[t]{2}{*}{ 5Y Ahead } & 0.85 & -155.41 & 98.54 & 0.01 & $<0.01$ \\
\hline & {$[0.78]$} & {$[-0.97]$} & [1.84] & & \\
\hline
\end{tabular}

The Table shows the predictability evidence from the projection of future macroeconomic growth rates on the current expected consumption growth $x$, good uncertainty $V_{g}$, and bad uncertainty $V_{b}$ : $\frac{1}{h} \sum_{j=1}^{h} \Delta y_{t+j}=a_{h}+b_{h}^{\prime}\left[x_{t}, V_{g t}, V_{b t}\right]+$ error. The Table reports the slope coefficients $b_{h}, t$-statistics, and the adjusted $R^{2}$ s for the regression horizons of $h=1,3$ and 5 years for the corresponding aggregate series $y$. The $p$-values are computed for the Wald test for the joint significance of good and bad uncertainty, $H 0: \beta_{g v}=\beta_{b v}=0$. Standard errors are Newey-West adjusted. The data are annual from 1930 to 2012 . 
Table 3: Macroeconomic Uncertainties and Investment

\begin{tabular}{|c|c|c|c|c|c|}
\hline & $x$ & $V_{b}$ & $V_{g}$ & $A d j-R^{2}$ & p-value \\
\hline \multicolumn{6}{|c|}{ Gross Private Capital Investment Growth: } \\
\hline 1Y Ahead & $\begin{array}{l}24.85 \\
{[4.42]}\end{array}$ & $\begin{array}{c}-2309.41 \\
{[-2.85]}\end{array}$ & $\begin{array}{c}912.46 \\
{[3.41]}\end{array}$ & 0.40 & $<0.01$ \\
\hline 3Y Ahead & $\begin{array}{c}7.76 \\
{[2.61]}\end{array}$ & $\begin{array}{c}-891.16 \\
{[-2.18]}\end{array}$ & $\begin{array}{l}542.32 \\
{[3.60]}\end{array}$ & 0.28 & $<0.01$ \\
\hline 5Y Ahead & $\begin{array}{c}3.53 \\
{[2.46]}\end{array}$ & $\begin{array}{c}-399.32 \\
{[-2.17]}\end{array}$ & $\begin{array}{c}287.53 \\
{[4.31]}\end{array}$ & 0.29 & $<0.01$ \\
\hline \multicolumn{6}{|c|}{ Nonresidential Capital Investment Growth: } \\
\hline 1Y Ahead & $\begin{array}{l}13.81 \\
{[6.74]}\end{array}$ & $\begin{array}{c}-789.80 \\
{[-1.83]}\end{array}$ & $\begin{array}{c}226.19 \\
{[1.51]}\end{array}$ & 0.45 & 0.07 \\
\hline 3Y Ahead & $\begin{array}{c}5.72 \\
{[3.04]}\end{array}$ & $\begin{array}{c}-272.28 \\
{[-1.26]}\end{array}$ & $\begin{array}{l}167.58 \\
{[2.11]}\end{array}$ & 0.22 & $<0.01$ \\
\hline 5Y Ahead & $\begin{array}{c}2.90 \\
{[3.44]}\end{array}$ & $\begin{array}{c}-124.54 \\
{[-1.01]}\end{array}$ & $\begin{array}{l}93.97 \\
{[2.15]}\end{array}$ & 0.18 & 0.01 \\
\hline \multicolumn{6}{|c|}{ R\&D Investment Growth: } \\
\hline 1Y Ahead & $\begin{array}{c}4.45 \\
{[4.05]}\end{array}$ & $\begin{array}{c}-822.83 \\
{[-2.43]}\end{array}$ & $\begin{array}{l}571.37 \\
{[2.16]}\end{array}$ & 0.28 & 0.05 \\
\hline 3Y Ahead & $\begin{array}{c}1.53 \\
{[2.59]}\end{array}$ & $\begin{array}{c}-980.22 \\
{[-2.59]}\end{array}$ & $\begin{array}{c}885.88 \\
{[4.76]}\end{array}$ & 0.23 & $<0.01$ \\
\hline 5Y Ahead & $\begin{array}{c}0.59 \\
{[1.59]}\end{array}$ & $\begin{array}{c}-847.67 \\
{[-2.88]}\end{array}$ & $\begin{array}{l}775.23 \\
{[4.86]}\end{array}$ & 0.24 & $<0.01$ \\
\hline \multicolumn{6}{|c|}{ R\&D Stock Growth: } \\
\hline 1Y Ahead & $\begin{array}{c}1.13 \\
{[3.83]}\end{array}$ & $\begin{array}{c}-983.80 \\
{[-3.31]}\end{array}$ & $\begin{array}{c}308.73 \\
{[1.74]}\end{array}$ & 0.55 & $<0.01$ \\
\hline 3Y Ahead & $\begin{array}{c}1.05 \\
{[3.60]}\end{array}$ & $\begin{array}{r}-950.27 \\
{[-2.86]}\end{array}$ & $\begin{array}{l}342.17 \\
{[1.57]}\end{array}$ & 0.46 & $<0.01$ \\
\hline 5Y Ahead & $\begin{array}{c}0.68 \\
{[2.54]}\end{array}$ & $\begin{array}{c}-998.32 \\
{[-2.86]}\end{array}$ & $\begin{array}{l}428.55 \\
{[1.81]}\end{array}$ & 0.41 & $<0.01$ \\
\hline \multicolumn{6}{|c|}{$\begin{array}{l}\text { Utility Patents Count } \\
\text { Growth: }\end{array}$} \\
\hline 1Y Ahead & $\begin{array}{c}2.57 \\
{[1.72]}\end{array}$ & $\begin{array}{c}-209.98 \\
{[-1.01]}\end{array}$ & $\begin{array}{l}13.11 \\
{[0.15]}\end{array}$ & 0.11 & 0.11 \\
\hline 3Y Ahead & $\begin{array}{c}2.40 \\
{[1.88]}\end{array}$ & $\begin{array}{c}-158.15 \\
{[-1.78]}\end{array}$ & $\begin{array}{l}18.55 \\
{[0.64]}\end{array}$ & 0.13 & 0.02 \\
\hline 5Y Ahead & $\begin{array}{c}1.54 \\
{[1.96]}\end{array}$ & $\begin{array}{c}-159.60 \\
{[-1.94]}\end{array}$ & $\begin{array}{l}26.64 \\
{[0.92]}\end{array}$ & 0.14 & $<0.01$ \\
\hline
\end{tabular}

The Table shows the predictability evidence from the projection of future investment growth rates on the current expected consumption growth $x$, good uncertainty $V_{g}$, and bad uncertainty $V_{b}$ : $\frac{1}{h} \sum_{j=1}^{h} \Delta y_{t+j}=a_{h}+b_{h}^{\prime}\left[x_{t}, V_{g t}, V_{b t}\right]+$ error. The Table reports the slope coefficients $b_{h}, t$-statistics, and the adjusted $R^{2}$ s for the regression horizons of $h=1,3$ and 5 years for the corresponding investment series $y$. The $p$-values are computed for the Wald test for the joint significance of good and bad uncertainty, $H 0: \beta_{g v}=\beta_{b v}=0$. Standard errors are Newey-West adjusted. R\&D investment data are from 1954 to 2008, R\&D stock data are from 1960 to 2007, and all the other data are annual from 1930 to 2012. 
Table 4: Macroeconomic Uncertainties and Aggregate Prices

\begin{tabular}{|c|c|c|c|c|c|}
\hline \multicolumn{6}{|c|}{ Panel A: Level-Based Projection } \\
\hline & $x$ & $V_{b}$ & $V_{g}$ & $A d j-R^{2}$ & p-value \\
\hline Market price- & 8.82 & -2313.28 & 279.27 & 0.21 & $<0.01$ \\
\hline dividend ratio & {$[0.94]$} & {$[-2.67]$} & {$[0.93]$} & & \\
\hline Real Risk-Free Rate & 0.05 & -222.24 & 80.50 & 0.21 & $<0.01$ \\
\hline & {$[0.08]$} & {$[-2.36]$} & {$[2.74]$} & & \\
\hline Default Spread & -0.36 & 50.54 & -3.80 & 0.47 & $<0.01$ \\
\hline & {$[-1.81]$} & {$[2.99]$} & {$[-0.52]$} & & \\
\hline \multicolumn{6}{|c|}{ Panel B: First Difference-Based Projection } \\
\hline & $\Delta x$ & $\Delta V_{b}$ & $\Delta V_{g}$ & $A d j-R^{2}$ & p-value \\
\hline \multirow{2}{*}{$\begin{array}{l}\Delta \text { Market price- } \\
\text { dividend ratio }\end{array}$} & 18.57 & -1353.26 & 448.49 & 0.61 & $<0.01$ \\
\hline & {$[9.97]$} & {$[-4.21]$} & {$[3.11]$} & & \\
\hline \multirow[t]{2}{*}{$\Delta$ Real Risk-Free Rate } & 0.01 & -107.47 & 31.75 & 0.16 & $<0.01$ \\
\hline & {$[0.04]$} & {$[-1.65]$} & {$[1.19]$} & & \\
\hline \multirow[t]{2}{*}{$\Delta$ Default Spread } & -0.26 & 40.46 & -10.64 & 0.30 & 0.01 \\
\hline & {$[-2.61]$} & {$[2.84]$} & {$[-1.98]$} & & \\
\hline
\end{tabular}

The Table reports the evidence from the projections of the aggregate asset-price variables on the contemporaneous expected consumption growth $x$, and the good and bad uncertainty variables, $V_{g}$ and $V_{b}$. Panel A shows the regression results based on the levels of the variables, and Panel $\mathrm{B}$ shows the output for the first differences. The Table reports the slope coefficients, $t$-statistics, the adjusted $R^{2} \mathrm{~s}$, and the $p$-values for the Wald test for the joint significance of good and bad uncertainty, $H 0: \beta_{g v}=\beta_{b v}=0$. Standard errors are Newey-West adjusted. The data are annual from 1930 to 2012 . 
Table 5: Asset-Pricing Implications

\begin{tabular}{ccc}
\hline \hline Panel A: Market-Prices of Risk & \multicolumn{1}{c}{$\Lambda / 100)$} \\
$\lambda_{x}$ & $\lambda_{b v}$ & $\lambda_{g v}$ \\
\hline 0.92 & -9.13 & 9.00 \\
\hline
\end{tabular}

Panel B: Exposures to Risks $(\beta / 100)$

\begin{tabular}{lccc} 
& $\beta_{x}$ & $\beta_{b v}$ & $\beta_{g v}$ \\
\cline { 2 - 4 } MARKET & 24.89 & -1807.47 & 701.42 \\
BM1 & 24.15 & -1600.27 & 586.48 \\
BM2 & 21.44 & -1685.00 & 582.57 \\
BM3 & 22.97 & -1537.51 & 587.84 \\
BM4 & 28.10 & -1411.45 & 627.90 \\
BM5 & 28.23 & -1717.90 & 797.57 \\
BM6 & 30.43 & -1546.45 & 689.74 \\
BM7 & 31.93 & -1944.56 & 911.39 \\
BM8 & 34.44 & -1847.57 & 910.48 \\
BM9 & 34.19 & -1752.12 & 847.24 \\
BM10 & 40.30 & -1966.77 & 965.05 \\
& & & \\
SIZE1 & 45.59 & -2008.17 & 993.01 \\
SIZE2 & 43.14 & -2082.75 & 1035.08 \\
SIZE3 & 39.83 & -1662.52 & 883.17 \\
SIZE4 & 37.02 & -1829.05 & 839.59 \\
SIZE5 & 34.05 & -1705.51 & 743.68 \\
SIZE6 & 31.59 & -1583.45 & 663.55 \\
SIZE7 & 31.35 & -1779.84 & 791.92 \\
SIZE8 & 28.76 & -1780.87 & 785.20 \\
SIZE9 & 27.59 & -1804.50 & 779.07 \\
SIZE10 & 24.11 & -1543.92 & 592.73 \\
\hline
\end{tabular}

The Table shows the estimates of the market prices of risks (Panel A) and the exposures to expected growth, good uncertainty, and bad uncertainty risks in the cross-section of the equity portfolios. The cross-section includes the market, ten portfolios sorted on book-to-market (BM), and ten portfolios sorted on size (SIZE). The reported betas and the market prices of risks are divided by 100. Data are annual from 1930 to 2012. 
Table 6: Risk Premia Decomposition

\begin{tabular}{|c|c|c|c|c|c|c|c|c|}
\hline \multirow[b]{3}{*}{ MARKET } & \multicolumn{2}{|c|}{ Total } & \multicolumn{6}{|c|}{ Model Decomposition } \\
\hline & Model & Data & $R P_{x, x}$ & $R P_{v b, v b}$ & $R P_{v g, v g}$ & $R P_{x, v b}$ & $R P_{x, v g}$ & $R P_{v b, v g}$ \\
\hline & 7.74 & 7.58 & 9.79 & 1.61 & 3.46 & 0.68 & -3.15 & -4.66 \\
\hline BM1 & 7.63 & 6.82 & 9.50 & 1.43 & 2.89 & 0.61 & -2.74 & -4.06 \\
\hline BM2 & 6.59 & 7.37 & 8.44 & 1.50 & 2.87 & 0.63 & -2.64 & -4.21 \\
\hline BM3 & 7.24 & 7.55 & 9.04 & 1.37 & 2.90 & 0.58 & -2.71 & -3.95 \\
\hline BM4 & 9.18 & 7.73 & 11.06 & 1.26 & 3.10 & 0.56 & -3.01 & -3.79 \\
\hline BM5 & 8.99 & 8.93 & 11.11 & 1.53 & 3.93 & 0.66 & -3.58 & -4.67 \\
\hline BM6 & 9.93 & 9.39 & 11.97 & 1.38 & 3.40 & 0.61 & -3.29 & -4.15 \\
\hline BM7 & 10.16 & 9.45 & 12.57 & 1.74 & 4.50 & 0.75 & -4.08 & -5.31 \\
\hline BM8 & 11.14 & 11.64 & 13.55 & 1.65 & 4.49 & 0.72 & -4.15 & -5.12 \\
\hline BM9 & 11.12 & 12.00 & 13.45 & 1.56 & 4.18 & 0.69 & -3.94 & -4.83 \\
\hline BM10 & 13.18 & 13.46 & 15.86 & 1.76 & 4.76 & 0.78 & -4.53 & -5.45 \\
\hline SIZE1 & 15.07 & 15.78 & 17.94 & 1.79 & 4.90 & 0.81 & -4.79 & -5.58 \\
\hline SIZE2 & 14.12 & 13.10 & 16.98 & 1.86 & 5.11 & 0.83 & -4.85 & -5.79 \\
\hline SIZE3 & 13.22 & 12.87 & 15.67 & 1.48 & 4.36 & 0.68 & -4.24 & -4.73 \\
\hline SIZE4 & 12.11 & 12.15 & 14.57 & 1.63 & 4.14 & 0.73 & -4.00 & -4.96 \\
\hline SIZE5 & 11.13 & 11.62 & 13.40 & 1.52 & 3.67 & 0.68 & -3.59 & -4.55 \\
\hline SIZE6 & 10.33 & 10.95 & 12.43 & 1.41 & 3.27 & 0.63 & -3.24 & -4.17 \\
\hline SIZE7 & 10.09 & 10.60 & 12.34 & 1.59 & 3.91 & 0.69 & -3.66 & -4.78 \\
\hline SIZE8 & 9.14 & 9.59 & 11.32 & 1.59 & 3.87 & 0.68 & -3.55 & -4.77 \\
\hline SIZE9 & 8.70 & 8.74 & 10.86 & 1.61 & 3.84 & 0.69 & -3.49 & -4.80 \\
\hline SIZE10 & 7.65 & 6.85 & 9.49 & 1.38 & 2.92 & 0.59 & -2.76 & -3.97 \\
\hline
\end{tabular}

The Table shows the cross-section of risk premia in the data and in the model, and the decomposition of the model risk premia into the compensations for each source of risk, such as expected growth $x$, good uncertainty $v g$, and bad uncertainty $v b$. The risk premia decompositions contain own compensations for individual risks (e.g., $R P_{x, x}$ ) and the components due to the interaction of different risks (e.g., $R P_{x, v g}$ ). The cross-section includes the market, ten portfolios sorted on book-to-market (BM), and ten portfolios sorted on size (SIZE). Data are annual from 1930 to 2012. 


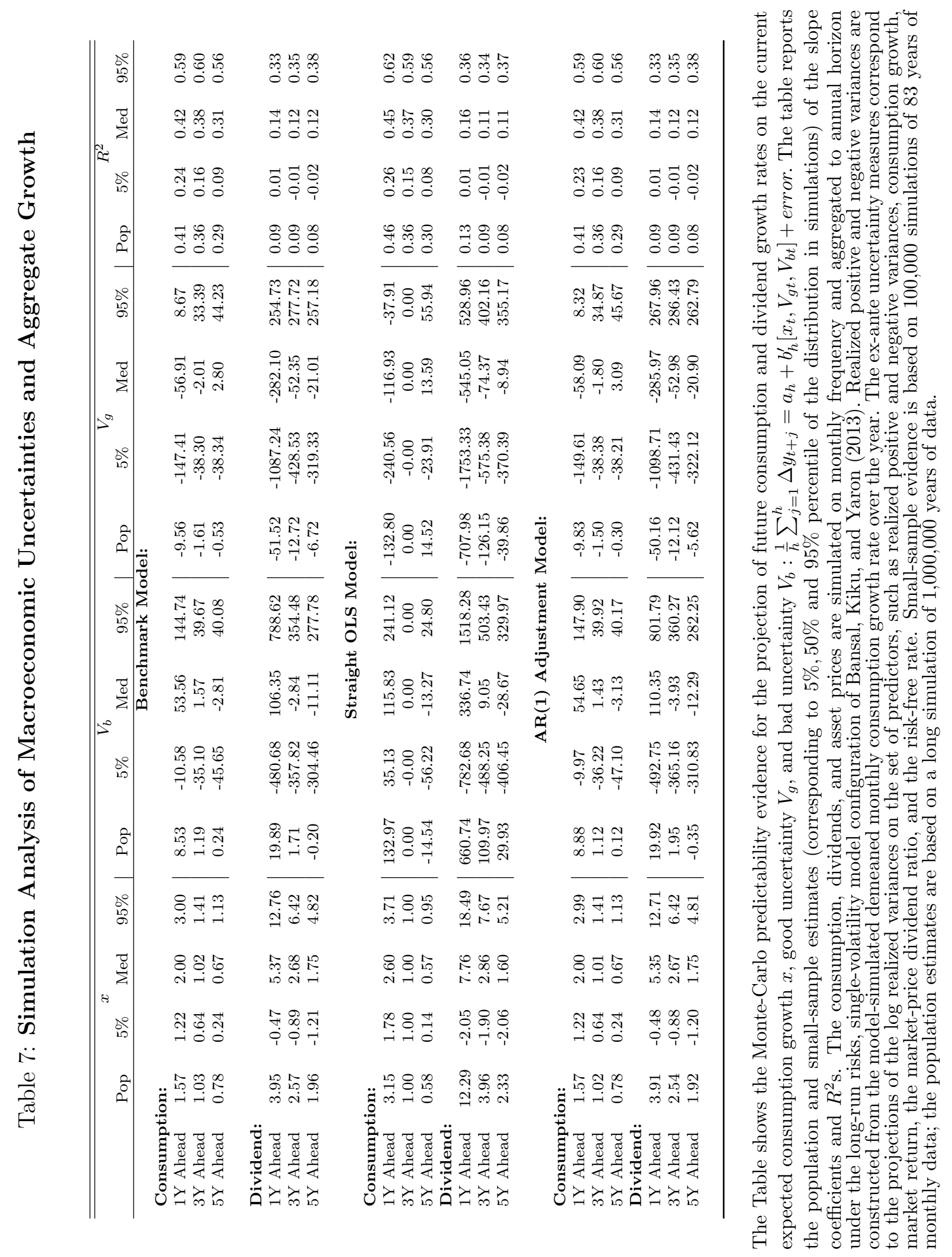


Table 8: Simulated Probabilities for Volatility Coefficients

\begin{tabular}{|c|c|c|c|}
\hline & $\operatorname{Pr}\left(b_{b v}<0\right)$ & $\operatorname{Pr}\left(b_{g v}>0\right)$ & $\operatorname{Pr}\left(b_{b v<0} \& b_{g v}>0\right)$ \\
\hline \multicolumn{4}{|c|}{ Benchmark Model: } \\
\hline Consumption Growth: & 0.05 & 0.04 & 0.03 \\
\hline Dividend Growth: & 0.24 & 0.12 & 0.09 \\
\hline Joint: & 0.02 & 0.01 & 0.01 \\
\hline \multicolumn{4}{|c|}{ Straight OLS Model: } \\
\hline Consumption Growth: & 0.004 & 0.004 & 0.002 \\
\hline Dividend Growth: & 0.21 & 0.13 & 0.11 \\
\hline Joint: & 0.002 & 0.001 & 0.001 \\
\hline \multicolumn{4}{|c|}{ AR(1) Adjustment Model: } \\
\hline Consumption Growth: & 0.05 & 0.04 & 0.03 \\
\hline Dividend Growth: & 0.24 & 0.12 & 0.09 \\
\hline Joint: & 0.02 & 0.01 & 0.01 \\
\hline
\end{tabular}

The Table shows the Monte-Carlo predictability evidence for the projection of future consumption and dividend growth rates on the current expected consumption growth $x$, good uncertainty $V_{g}$, and bad uncertainty $V_{b}: \frac{1}{h} \sum_{j=1}^{h} \Delta y_{t+j}=a_{h}+b_{h}^{\prime}\left[x_{t}, V_{g t}, V_{b t}\right]+$ error. The table reports the fraction of samples in which bad (good) uncertainty loadings at 1-, 3-, and 5-year maturities are all negative (positive). The data are simulated on monthly frequency and aggregated to annual horizon under the long-run risks, single-volatility model configuration of Bansal, Kiku, and Yaron (2013). Realized positive and negative variances are constructed from the model-simulated demeaned monthly consumption growth rate over the year. The ex-ante uncertainty measures correspond to the projections of the log realized variances on the set of predictors, such as realized positive and negative variances, consumption growth, market return, the market-price dividend ratio, and the risk-free rate. Small-sample evidence is based on 100,000 simulations of 83 years of monthly data. 
Table 9: Conditionally Demeaned Industrial Production-Based Uncertainties

\begin{tabular}{|c|c|c|c|c|}
\hline & $x$ & $V_{b}$ & $V_{g}$ & $A d j-R^{2}$ \\
\hline \multicolumn{5}{|c|}{ Panel A: Aggregate Growth Rate Predictability } \\
\hline \multirow[t]{2}{*}{ Consumption Growth } & 2.11 & -63.49 & 21.41 & 0.48 \\
\hline & {$[4.80]$} & {$[-1.03]$} & {$[0.79]$} & \\
\hline \multirow[t]{2}{*}{ GDP Growth } & 7.22 & -910.48 & 460.51 & 0.13 \\
\hline & {$[2.69]$} & {$[-1.39]$} & {$[1.29]$} & \\
\hline \multirow[t]{2}{*}{ Market Dividend Growth } & 7.26 & 76.37 & -154.09 & 0.29 \\
\hline & {$[3.41]$} & {$[0.29]$} & {$[-1.18]$} & \\
\hline \multirow[t]{2}{*}{ Earnings Growth } & 13.05 & -401.02 & 75.59 & 0.09 \\
\hline & {$[2.69]$} & {$[-0.67]$} & {$[0.26]$} & \\
\hline \multirow[t]{2}{*}{ Capital Investment Growth } & 24.56 & -1574.59 & 885.52 & 0.32 \\
\hline & {$[3.65]$} & {$[-1.59]$} & {$[2.01]$} & \\
\hline \multirow[t]{2}{*}{ R\&D Investment Growth } & 4.11 & -1046.42 & 594.90 & 0.22 \\
\hline & {$[4.92]$} & {$[-1.95]$} & {$[1.77]$} & \\
\hline \multicolumn{5}{|c|}{ Panel B: Aggregate Asset Prices } \\
\hline \multicolumn{5}{|c|}{ Level-Based Projections: } \\
\hline \multirow[t]{2}{*}{ Market price-dividend ratio } & 3.60 & -588.21 & -470.52 & 0.17 \\
\hline & {$[0.43]$} & {$[-0.47]$} & {$[-1.09]$} & \\
\hline \multirow[t]{2}{*}{ Real Risk-Free Rate } & -0.44 & -106.17 & 39.29 & 0.07 \\
\hline & {$[-0.71]$} & {$[-1.45]$} & {$[1.53]$} & \\
\hline \multirow[t]{2}{*}{ Default Spread } & -0.44 & 63.02 & -13.20 & 0.45 \\
\hline & {$[-2.43]$} & {$[2.66]$} & {$[-1.15]$} & \\
\hline \multicolumn{5}{|c|}{ First Difference-Based Projections: } \\
\hline \multirow[t]{2}{*}{$\Delta$ Market price-dividend ratio } & 21.25 & -706.94 & 367.33 & 0.52 \\
\hline & {$[9.35]$} & {$[-2.23]$} & {$[3.22]$} & \\
\hline \multirow[t]{2}{*}{$\Delta$ Real Risk-Free Rate } & 0.36 & -111.12 & 41.35 & 0.15 \\
\hline & {$[1.53]$} & {$[-2.17]$} & {$[1.57]$} & \\
\hline \multirow[t]{2}{*}{$\Delta$ Default Spread } & -0.33 & 33.99 & -11.47 & 0.22 \\
\hline & {$[-2.83]$} & {$[2.52]$} & {$[-2.28]$} & \\
\hline \multicolumn{5}{|c|}{ Panel C: Asset-Pricing Implications } \\
\hline Prices of Risk $(\Lambda / 100)$ & 1.00 & -7.93 & 25.76 & \\
\hline Market Exposures $(\beta / 100)$ & 31.98 & -1866.66 & 988.21 & \\
\hline
\end{tabular}

The Table presents the summary of the macroeconomic and asset-price implications of the growth and uncertainty channels using the alternative measures of good and bad uncertainty based on the monthly, conditionally demeaned, industrial-production data and the full-sample period. The conditional mean is removed by using the residuals obtained from fitting an $\operatorname{AR}(1)$ to industrial production growth. Panel A documents the slope coefficients, $t$-statistics and the $R^{2}$ in the projections of one-year ahead macroeconomic growth rates on the expected growth $x$, good uncertainty $V_{g}$, and bad uncertainty $V_{b}$. Panel B shows the evidence from the contemporaneous regressions of the aggregate asset prices on these factors, both in levels and in first differences. Panel C shows the estimates of the market prices of risks and the market return exposures to expected growth, good uncertainty, and bad uncertainty risk. The market prices of risks are estimated using the crosssection of the assets which includes the market return, ten portfolios sorted on book-to-market, and ten portfolios sorted on size. The reported betas and the market prices of risks are divided by 100 . Data are annual from 1930 to 2012. 
Table 10: Industrial Production-Based Uncertainties with Shifted Cutoff

\begin{tabular}{|c|c|c|c|c|}
\hline & $x$ & $V_{b}$ & $V_{g}$ & $A d j-R^{2}$ \\
\hline \multicolumn{5}{|c|}{ Panel A: Aggregate Growth Rate Predictability } \\
\hline \multirow[t]{2}{*}{ Consumption Growth } & 2.01 & -80.25 & 16.91 & 0.52 \\
\hline & {$[5.14]$} & {$[-1.56]$} & {$[1.09]$} & \\
\hline \multirow[t]{2}{*}{ GDP Growth } & 4.48 & -680.39 & 229.82 & 0.05 \\
\hline & {$[6.60]$} & {$[-1.58]$} & {$[1.50]$} & \\
\hline \multirow[t]{2}{*}{ Market Dividend Growth } & 8.78 & -459.88 & 38.09 & 0.40 \\
\hline & {$[4.37]$} & {$[-1.96]$} & {$[0.50]$} & \\
\hline \multirow[t]{2}{*}{ Earnings Growth } & 12.26 & -724.71 & 129.06 & 0.10 \\
\hline & {$[3.58]$} & {$[-1.19]$} & {$[0.60]$} & \\
\hline \multirow[t]{2}{*}{ Capital Investment Growth } & 24.08 & -2319.51 & 830.56 & 0.38 \\
\hline & {$[4.28]$} & {$[-2.31]$} & {$[2.65]$} & \\
\hline \multirow[t]{2}{*}{ R\&D Investment Growth } & 4.39 & -724.28 & 582.91 & 0.28 \\
\hline & {$[4.02]$} & {$[-2.73]$} & {$[2.31]$} & \\
\hline \multicolumn{5}{|c|}{ Panel B: Aggregate Asset Prices } \\
\hline \multicolumn{5}{|c|}{ Level-Based Projections: } \\
\hline \multirow[t]{2}{*}{ Market price-dividend ratio } & 10.46 & -3075.22 & 493.02 & 0.24 \\
\hline & {$[1.16]$} & {$[-2.96]$} & {$[1.49]$} & \\
\hline \multirow[t]{2}{*}{ Real Risk-Free Rate } & -0.02 & -226.10 & 73.65 & 0.19 \\
\hline & {$[-0.03]$} & {$[-2.14]$} & {$[2.51]$} & \\
\hline \multirow[t]{2}{*}{ Default Spread } & -0.41 & 72.97 & -10.93 & 0.52 \\
\hline & {$[-2.42]$} & {$[4.30]$} & {$[-1.40]$} & \\
\hline \multicolumn{5}{|c|}{ First Difference-Based Projections: } \\
\hline \multirow[t]{2}{*}{$\Delta$ Market price-dividend ratio } & 18.54 & -1588.31 & 445.77 & 0.61 \\
\hline & {$[10.25]$} & {$[-4.72]$} & {$[3.58]$} & \\
\hline \multirow[t]{2}{*}{$\Delta$ Real Risk-Free Rate } & -0.01 & -117.20 & 28.81 & 0.14 \\
\hline & {$[-0.06]$} & {$[-1.53]$} & {$[1.10]$} & \\
\hline \multirow[t]{2}{*}{$\Delta$ Default Spread } & -0.28 & 57.12 & -14.03 & 0.39 \\
\hline & {$[-2.89]$} & {$[3.13]$} & {$[-2.21]$} & \\
\hline \multicolumn{5}{|c|}{ Panel C: Asset-Pricing Implications } \\
\hline Prices of Risk $(\Lambda / 100)$ & 0.91 & -0.99 & 4.63 & \\
\hline Market Exposures $(\beta / 100)$ & 24.05 & -1910.66 & 632.48 & \\
\hline
\end{tabular}

The Table presents the summary of the macroeconomic and asset-price implications of the growth and uncertainty channels using the alternative measures of good and bad uncertainty based on the monthly industrial-production data, using shifted cutoff between good and bad uncertainty observations, and the full-sample period. The ex-post positive (negative) semi-variance is computed using observations above (below) the 75th percentile of industrial production growth. Panel A documents the slope coefficients, $t$-statistics and the $R^{2}$ in the projections of one-year ahead macroeconomic growth rates on the expected growth $x$, good uncertainty $V_{g}$, and bad uncertainty $V_{b}$. Panel B shows the evidence from the contemporaneous regressions of the aggregate asset prices on these factors, both in levels and in first differences. Panel $\mathrm{C}$ shows the estimates of the market prices of risks and the market return exposures to expected growth, good uncertainty, and bad uncertainty risk. The market prices of risks are estimated using the cross-section of the assets which includes the market return, ten portfolios sorted on book-to-market, and ten portfolios sorted on size. The reported betas and the market prices of risks are divided by 100. Data are annual from 1930 to 2012. 
Table 11: Earnings-Based Uncertainties

\begin{tabular}{|c|c|c|c|c|}
\hline & $x$ & $V_{b}$ & $V_{g}$ & $A d j-R^{2}$ \\
\hline \multicolumn{5}{|c|}{ Panel A: Aggregate Growth Rate Predictability } \\
\hline \multirow[t]{2}{*}{ Consumption Growth } & 1.86 & -160.58 & 41.10 & 0.53 \\
\hline & {$[7.10]$} & {$[-2.00]$} & {$[1.97]$} & \\
\hline \multirow[t]{2}{*}{ GDP Growth } & 4.86 & -371.75 & 98.78 & 0.05 \\
\hline & {$[2.00]$} & {$[-2.73]$} & {$[2.84]$} & \\
\hline \multirow[t]{2}{*}{ Market Dividend Growth } & 6.28 & -1448.37 & 354.80 & 0.37 \\
\hline & {$[3.01]$} & {$[-3.99]$} & {$[3.85]$} & \\
\hline \multirow[t]{2}{*}{ Earnings Growth } & 4.12 & -1319.52 & 166.00 & 0.21 \\
\hline & {$[0.67]$} & {$[-1.60]$} & {$[0.86]$} & \\
\hline \multirow[t]{2}{*}{ Capital Investment Growth } & 18.98 & -3498.01 & 901.57 & 0.43 \\
\hline & {$[5.40]$} & {$[-3.17]$} & {$[3.21]$} & \\
\hline \multirow[t]{2}{*}{ R\&D Investment Growth } & 2.63 & 720.54 & -195.27 & 0.26 \\
\hline & {$[2.72]$} & {$[2.55]$} & {$[-2.69]$} & \\
\hline \multirow[t]{2}{*}{ R\&D Stock Growth } & 0.59 & -117.48 & 63.76 & -0.01 \\
\hline & {$[1.11]$} & {$[-0.50]$} & {$[1.54]$} & \\
\hline \multicolumn{5}{|c|}{ Panel B: Aggregate Asset Prices } \\
\hline \multicolumn{5}{|c|}{ Level-Based Projections: } \\
\hline \multirow[t]{2}{*}{ Market price-dividend ratio } & 2.38 & -5282.53 & 1377.15 & 0.13 \\
\hline & {$[0.37]$} & {$[-2.59]$} & {$[2.66]$} & \\
\hline \multirow[t]{2}{*}{ Real Risk-Free Rate } & -0.40 & 51.03 & -24.48 & -0.01 \\
\hline & {$[-0.39]$} & {$[0.25]$} & {$[-0.44]$} & \\
\hline \multirow[t]{2}{*}{ Default Spread } & -0.08 & 76.82 & -15.42 & 0.19 \\
\hline & {$[-0.51]$} & {$[1.68]$} & {$[-1.26]$} & \\
\hline \multicolumn{5}{|c|}{ First Difference-Based Projections: } \\
\hline \multirow[t]{2}{*}{$\Delta$ Market price-dividend ratio } & 16.81 & -1688.33 & 399.38 & 0.61 \\
\hline & {$[7.89]$} & {$[-4.93]$} & {$[4.48]$} & \\
\hline \multirow[t]{2}{*}{$\Delta$ Real Risk-Free Rate } & -0.44 & -74.01 & 12.36 & 0.05 \\
\hline & {$[-0.96]$} & {$[-2.02]$} & {$[1.24]$} & \\
\hline \multirow[t]{2}{*}{$\Delta$ Default Spread } & -0.09 & 39.07 & -6.31 & 0.44 \\
\hline & {$[-1.15]$} & {$[1.28]$} & {$[-0.81]$} & \\
\hline \multicolumn{5}{|c|}{ Panel C: Asset-Pricing Implications } \\
\hline Prices of Risk $(\Lambda / 100)$ & 0.83 & -96.17 & 32.20 & \\
\hline Market Exposures $(\beta / 100)$ & 26.04 & -1371.85 & 368.57 & \\
\hline
\end{tabular}

The Table presents the summary of the macroeconomic and asset-price implications of the growth and uncertainty channels using the alternative measures of good and bad uncertainty based on the monthly corporate earnings data. Panel A documents the slope coefficients, $t$-statistics and the $R^{2}$ in the projections of one-year ahead macroeconomic growth rates on the expected growth $x$, good uncertainty $V_{g}$, and bad uncertainty $V_{b}$. Panel B shows the evidence from the contemporaneous regressions of the aggregate asset prices on these factors, both in levels and in first differences. Panel $\mathrm{C}$ shows the estimates of the market prices of risks and the market return exposures to expected growth, good uncertainty, and bad uncertainty risk. The market prices of risks are estimated using the cross-section of the assets which includes the market return, ten portfolios sorted on book-tomarket, and ten portfolios sorted on size. The reported betas and the market prices of risks are divided by 100. Data are annual from 1930 to 2012 . 
Table 12: Benchmark Uncertainties: Post-War Sample

\begin{tabular}{|c|c|c|c|c|}
\hline Panel A: Aggre & $\begin{array}{l}x \\
\text { rowth F }\end{array}$ & $\begin{array}{l}V_{b} \\
\text { te Predict }\end{array}$ & $\begin{array}{l}V_{g} \\
\text { ability }\end{array}$ & $A d j-R^{2}$ \\
\hline Consumption Growth & $\begin{array}{l}1.43 \\
{[6.27]}\end{array}$ & $\begin{array}{l}-275.72 \\
{[-3.57]}\end{array}$ & $\begin{array}{l}123.23 \\
{[2.88]}\end{array}$ & 0.41 \\
\hline GDP Growth & $\begin{array}{l}2.27 \\
{[1.33]}\end{array}$ & $\begin{array}{l}-1127.75 \\
{[-2.41]}\end{array}$ & $\begin{array}{l}1174.93 \\
{[2.09]}\end{array}$ & 0.44 \\
\hline Market Dividend Growth & $\begin{array}{l}2.41 \\
{[1.26]}\end{array}$ & $\begin{array}{l}-362.83 \\
{[-0.59]}\end{array}$ & $\begin{array}{l}136.85 \\
{[0.51]}\end{array}$ & -0.01 \\
\hline Earnings Growth & $\begin{array}{l}11.39 \\
{[1.78]}\end{array}$ & $\begin{array}{l}-1941.22 \\
{[-0.77]}\end{array}$ & $\begin{array}{l}666.54 \\
{[0.67]}\end{array}$ & 0.02 \\
\hline Capital Investment Growth & $\begin{array}{l}8.33 \\
{[3.45]} \\
\end{array}$ & $\begin{array}{l}-2231.30 \\
{[-4.51]}\end{array}$ & $\begin{array}{l}1813.75 \\
{[3.88]}\end{array}$ & 0.42 \\
\hline \multicolumn{5}{|c|}{ Panel B: Aggregate Asset Prices } \\
\hline Market price-dividend ratio & $\begin{array}{l}-5.92 \\
{[-0.65]}\end{array}$ & $\begin{array}{l}-3987.38 \\
{[-1.59]}\end{array}$ & $\begin{array}{l}-1011.95 \\
{[-0.75]}\end{array}$ & 0.34 \\
\hline Real Risk-Free Rate & $\begin{array}{l}1.32 \\
{[3.04]}\end{array}$ & $\begin{array}{l}-440.50 \\
{[-2.35]}\end{array}$ & $\begin{array}{l}80.05 \\
{[1.12]}\end{array}$ & 0.37 \\
\hline Default Spread & $\begin{array}{l}-0.41 \\
{[-3.15]}\end{array}$ & $\begin{array}{l}113.33 \\
{[1.66]}\end{array}$ & $\begin{array}{l}-49.41 \\
{[-2.11]}\end{array}$ & 0.33 \\
\hline \multicolumn{5}{|c|}{ First Difference-Based Projections: } \\
\hline$\Delta$ Market price-dividend ratio & $\begin{array}{l}20.93 \\
{[12.62]}\end{array}$ & $\begin{array}{l}-2740.74 \\
{[-4.31]}\end{array}$ & $\begin{array}{l}665.55 \\
{[2.70]}\end{array}$ & 0.61 \\
\hline$\Delta$ Real Risk-Free Rate & $\begin{array}{l}0.37 \\
{[1.09]}\end{array}$ & $\begin{array}{l}-364.57 \\
{[-3.39]}\end{array}$ & $\begin{array}{l}174.82 \\
{[5.60]}\end{array}$ & 0.46 \\
\hline$\Delta$ Default Spread & $\begin{array}{l}-0.40 \\
{[-3.63]}\end{array}$ & $\begin{array}{l}122.58 \\
{[2.99]}\end{array}$ & $\begin{array}{l}-4.44 \\
{[-0.77]}\end{array}$ & 0.61 \\
\hline \multicolumn{5}{|c|}{ Panel C: Asset Pricing Implications } \\
\hline $\begin{array}{l}\text { Prices of Risk }(\Lambda / 100) \\
\text { Market Exposures }(\beta / 100)\end{array}$ & $\begin{array}{l}0.83 \\
29.34\end{array}$ & $\begin{array}{l}-40.58 \\
-3196.44\end{array}$ & $\begin{array}{l}23.08 \\
1205.82\end{array}$ & \\
\hline
\end{tabular}

The Table presents the summary of the macroeconomic and asset-price implications of the growth and uncertainty channels using the benchmark uncertainty measures in the post-war period. Panel A documents the slope coefficients, $t$-statistics and the $R^{2}$ in the projections of one-year ahead macroeconomic growth rates on the expected growth $x$, good uncertainty $V_{g}$, and bad uncertainty $V_{b}$. Panel B shows the evidence from the contemporaneous regressions of the aggregate asset prices on these factors, both in levels and in first differences. Panel $\mathrm{C}$ shows the estimates of the market prices of risks and the market return exposures to expected growth, good uncertainty, and bad uncertainty risk. The market prices of risks are estimated using the cross-section of the assets which includes the market return, ten portfolios sorted on book-to-market, and ten portfolios sorted on size. The reported betas and the market prices of risks are divided by 100. Data are annual from 1947 to 2012. 
Table 13: Earnings-Based Uncertainties: Post-War Sample

\begin{tabular}{|c|c|c|c|c|}
\hline \multirow{2}{*}{\multicolumn{5}{|c|}{$\begin{array}{ccc}x & V_{b} & V_{g} \\
\text { Panel A. Aggregate Growth } & \text { Rate Predictability }\end{array}$}} \\
\hline & & & & \\
\hline \multirow[t]{2}{*}{ Consumption Growth } & 1.10 & 166.92 & -45.10 & 0.37 \\
\hline & {$[5.50]$} & {$[2.06]$} & {$[-2.16]$} & \\
\hline \multirow[t]{2}{*}{ GDP Growth } & 8.00 & -211.09 & 68.04 & 0.14 \\
\hline & {$[1.70]$} & {$[-0.86]$} & {$[0.96]$} & \\
\hline \multirow[t]{2}{*}{ Market Dividend Growth } & 2.22 & -1577.82 & 372.83 & 0.29 \\
\hline & {$[1.46]$} & {$[-3.32]$} & {$[3.03]$} & \\
\hline \multirow[t]{2}{*}{ Earnings Growth } & -3.80 & -3256.04 & 628.85 & 0.28 \\
\hline & {$[-0.39]$} & {$[-2.22]$} & {$[1.76]$} & \\
\hline \multirow[t]{2}{*}{ Capital Investment Growth } & 13.66 & -1189.16 & 291.99 & 0.27 \\
\hline & {$[3.04]$} & {$[-2.86]$} & {$[2.63]$} & \\
\hline \multirow[t]{2}{*}{ R\&D Investment Growth } & 6.85 & -477.49 & 99.64 & 0.45 \\
\hline & {$[6.70]$} & {$[-1.71]$} & {$[1.37]$} & \\
\hline \multicolumn{5}{|c|}{$\begin{array}{ll}\text { Panel B. Aggregate Asset Prices } \\
\end{array}$} \\
\hline \multicolumn{5}{|c|}{ Level-Based Projections: } \\
\hline \multirow[t]{2}{*}{ Market price-dividend ratio } & 9.90 & -11140.89 & 2899.59 & 0.20 \\
\hline & {$[1.48]$} & {$[-5.63]$} & {$[5.80]$} & \\
\hline \multirow[t]{2}{*}{ Real Risk-Free Rate } & -0.18 & 780.51 & -203.19 & 0.40 \\
\hline & {$[-0.48]$} & {$[3.94]$} & {$[-3.98]$} & \\
\hline \multirow[t]{2}{*}{ Default Spread } & -0.09 & 52.56 & -9.55 & 0.36 \\
\hline & {$[-1.26]$} & {$[1.07]$} & {$[-0.75]$} & \\
\hline \multicolumn{5}{|c|}{ First Difference-Based Projections: } \\
\hline \multirow[t]{2}{*}{$\Delta$ Market price-dividend ratio } & 14.94 & -199.26 & 8.93 & 0.56 \\
\hline & {$[9.53]$} & {$[-0.23]$} & {$[0.04]$} & \\
\hline \multirow[t]{2}{*}{$\Delta$ Real Risk-Free Rate } & 0.29 & 646.07 & -166.91 & 0.23 \\
\hline & {$[1.42]$} & {$[2.44]$} & {$[-2.42]$} & \\
\hline \multirow[t]{2}{*}{$\Delta$ Default Spread } & -0.07 & -35.64 & 13.02 & 0.62 \\
\hline & {$[-1.53]$} & {$[-2.17]$} & {$[3.03]$} & \\
\hline \multicolumn{5}{|c|}{ Panel C. Asset-Pricing Implications } \\
\hline Prices of Risk $(\Lambda / 100)$ & 2.98 & -2691.84 & 663.42 & \\
\hline Market Exposures $(\beta / 100)$ & 60.59 & -12008.91 & 3343.90 & \\
\hline
\end{tabular}

The Table presents the summary of the macroeconomic and asset-price implications of the growth and uncertainty channels using the alternative measures of good and bad uncertainty based on the monthly corporate earnings data and the post-war period. Panel A documents the slope coefficients, $t$-statistics and the $R^{2}$ in the projections of one-year ahead macroeconomic growth rates on the expected growth $x$, good uncertainty $V_{g}$, and bad uncertainty $V_{b}$. Panel B shows the evidence from the contemporaneous regressions of the aggregate asset prices on these factors, both in levels and in first differences. Panel $\mathrm{C}$ shows the estimates of the market prices of risks and the market return exposures to expected growth, good uncertainty, and bad uncertainty risk. The market prices of risks are estimated using the cross-section of the assets which includes the market return, ten portfolios sorted on book-to-market, and ten portfolios sorted on size. The reported betas and the market prices of risks are divided by 100. Data are annual from 1947 to 2012. 
Figure 1: Total Realized Variance

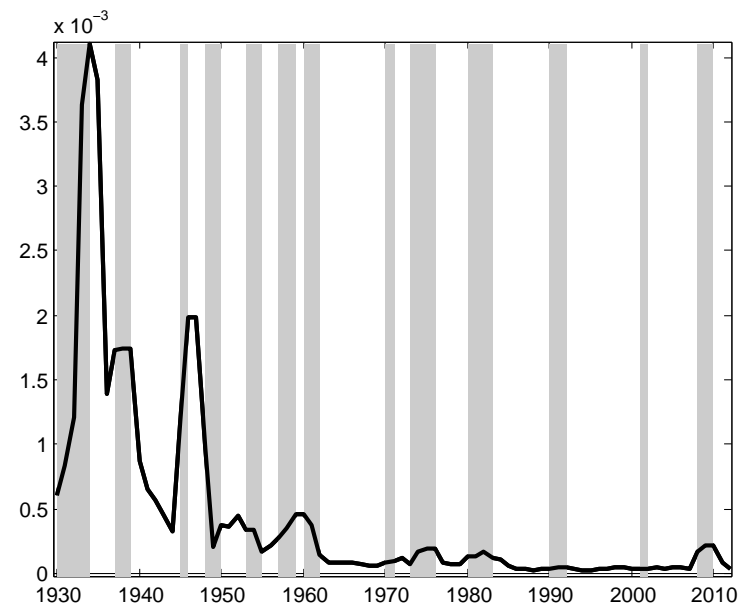

The Figure shows the time series plot of the total realized variance smoothed over a 3-year window. The total realized variance is based on the sum of squared observations of demeaned monthly industrial production growth over 1-year, re-scaled to match the unconditional variance of consumption growth. The shaded areas represent NBER recessions.

\section{Figure 2: Residual Positive Variance}

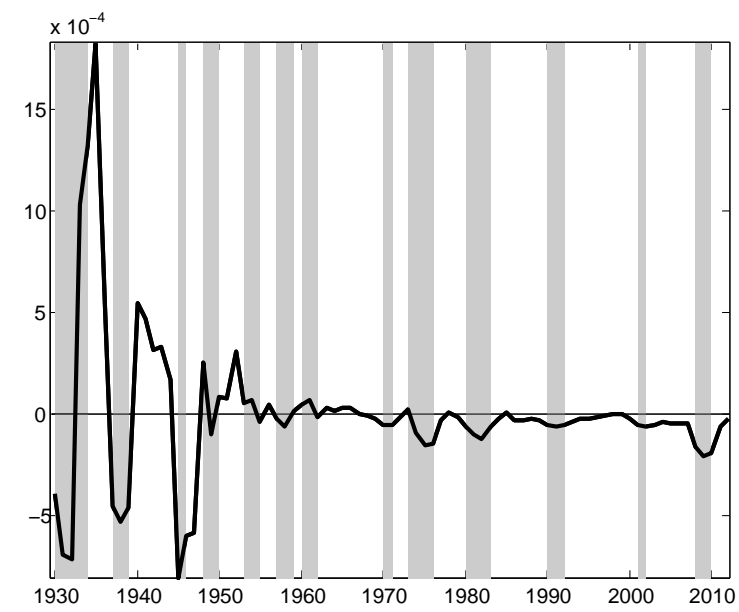

The Figure shows the time series plot of the residual positive variance, smoothed over a 3-year window, which is orthogonal to the negative variance. The positive and negative realized semivariances decompose the total realized variance into the components pertaining only to positive and negative movements in industrial production growth, respectively. The residual positive variance is computed from the projection of the positive realized semivariance onto the negative one. The shaded areas represent NBER recessions. 


\section{Figure 3: Realized and Predictive Log Volatilities}

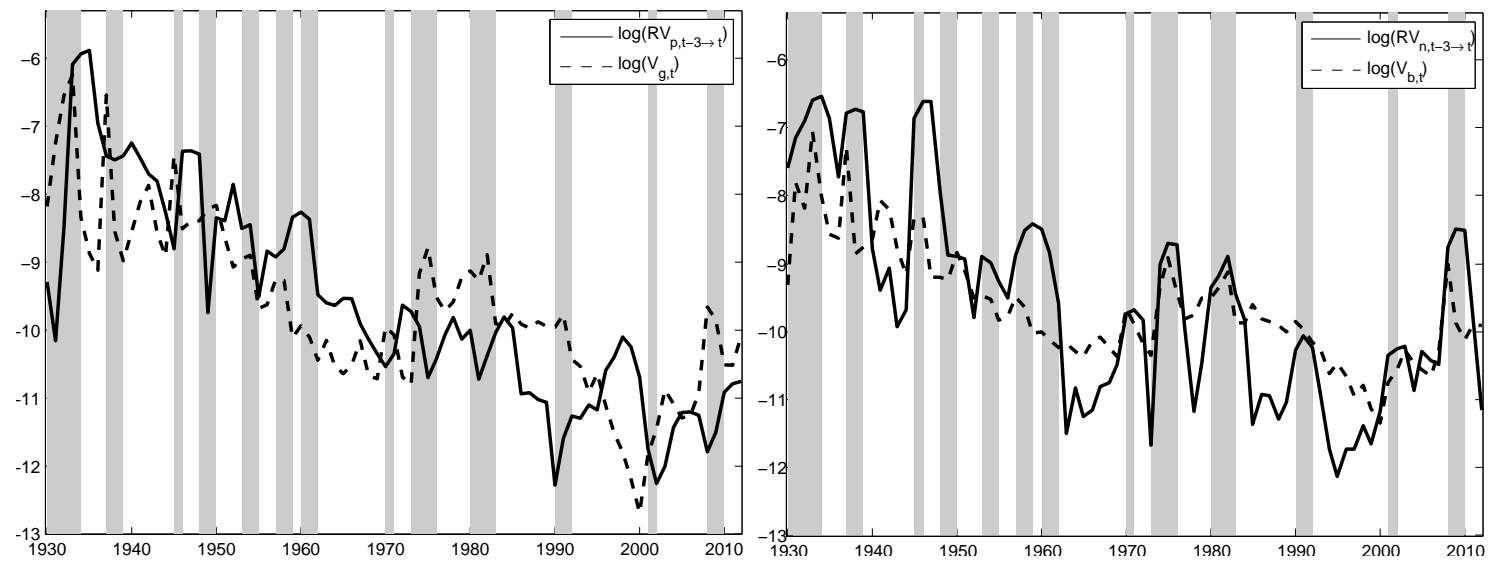

The Figure shows the time series plots of the log positive (left Panel) and negative (right Panel) realized variances and their predictive values from the projection. The shaded areas represent NBER recessions. The benchmark predictive variables in the projection include positive and negative realized semivariances, consumption growth rate, the real-market return, the market price-dividend ratio, the real risk-free rate, and the default spread.

Figure 4: Total Ex-Ante Uncertainty

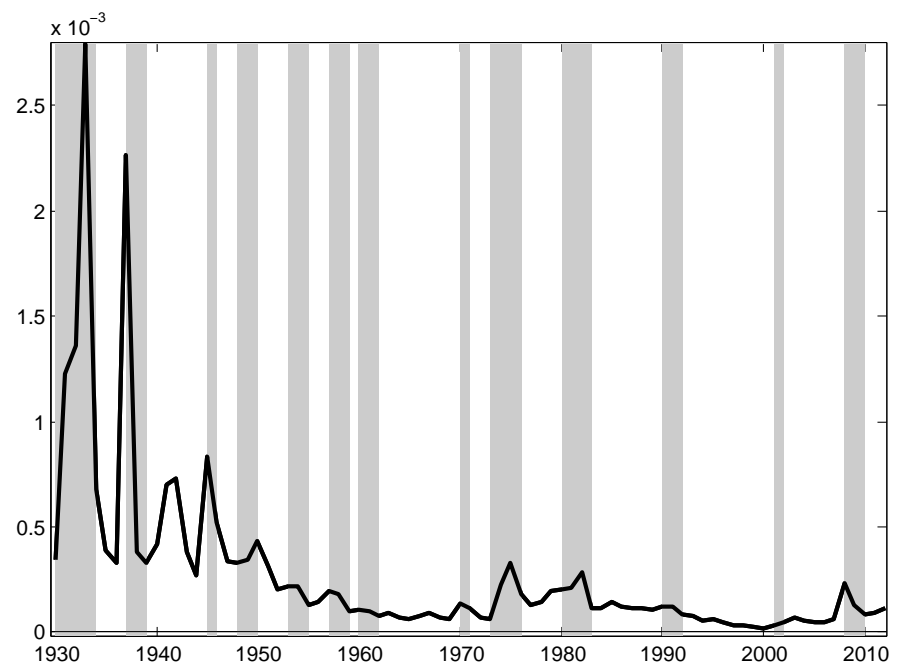

The Figure shows the time series plot of the total ex-ante uncertainty. The total ex-ante uncertainty is constructed from the predictive regressions of future overall realized variance. The shaded areas represent NBER recessions. 


\section{Figure 5: Residual Good Uncertainty}

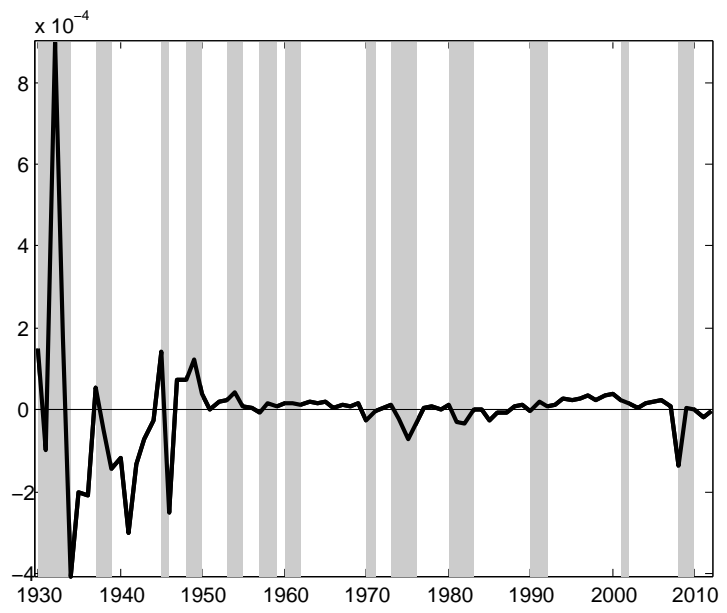

The Figure shows the time series plot of the residual good uncertainty which is orthogonal to the bad uncertainty. The good and bad uncertainties are constructed from the predictive regressions of future realized positive and negative variances, respectively. The residual good uncertainty is computed from the projection of the positive realized semivariance onto the negative one. The shaded areas represent NBER recessions. 


\section{Figure 6: Impulse Response of GDP to Macro Uncertainties}

(a) GDP Growth Response to Good Uncertainty Shock

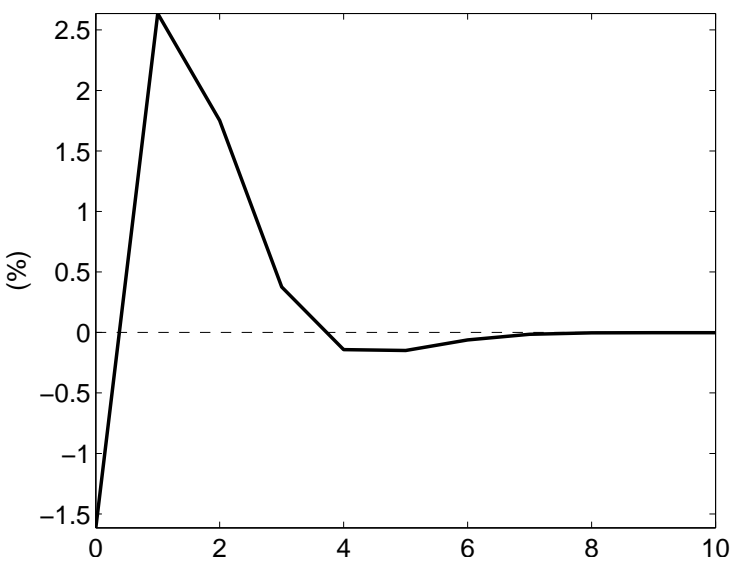

(b) GDP Growth Response to Bad Uncertainty Shock

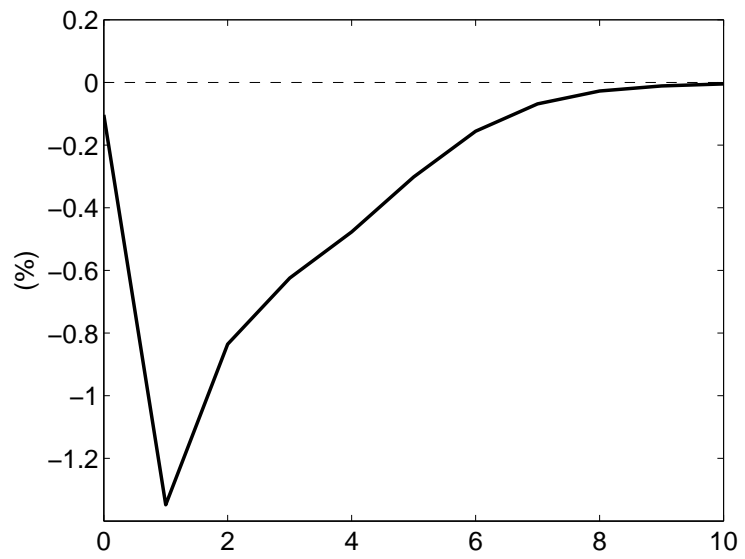

(c) GDP Growth Response to Total Uncertainty Shock

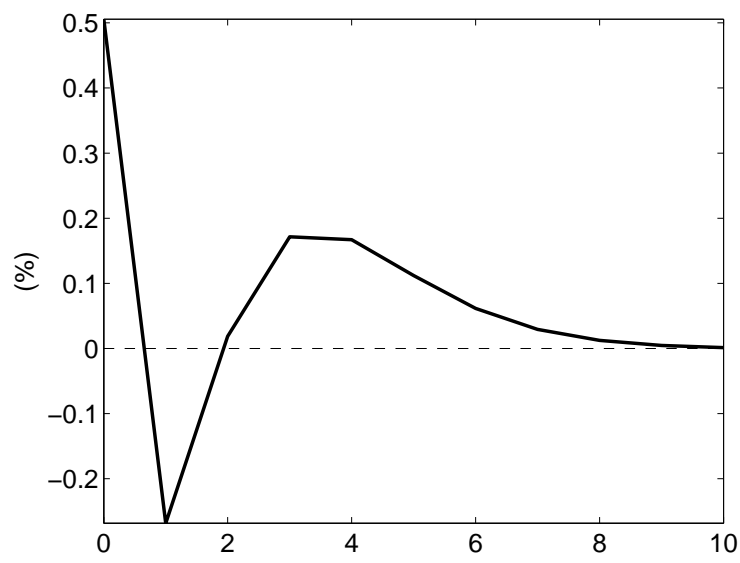

The Figure shows impulse responses of private GDP growth to one-standard deviation good, bad, and total uncertainty shocks. The impulse responses are computed from a $\operatorname{VAR}(1)$ which includes macroeconomic uncertainty measures (bad and good uncertainty for the first two panels, and total uncertainty for the last panel), expected consumption growth, and GDP growth rate. Data are annual from 1930 to 2012. 


\section{Figure 7: Impulse Response of Capital Investment to Macro Uncertainties}

(a) Capital Investment Growth Response to Good Uncertainty Shock

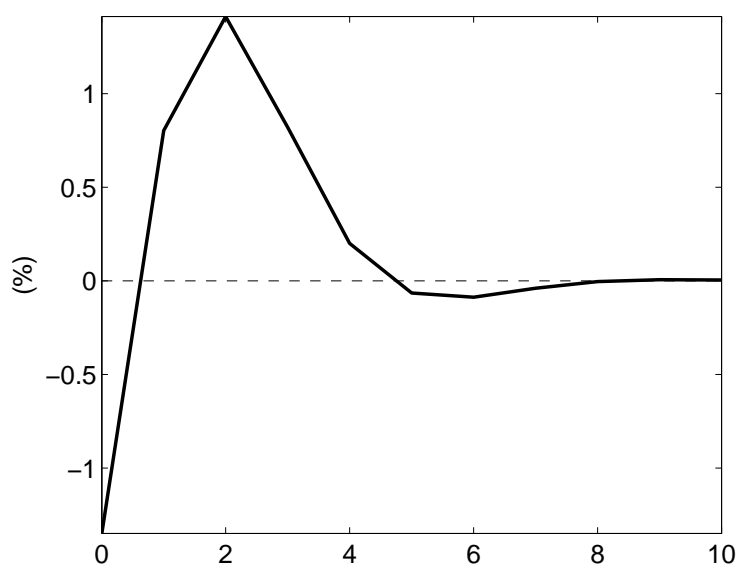

(b) Capital Investment Growth Response to Bad Uncertainty Shock

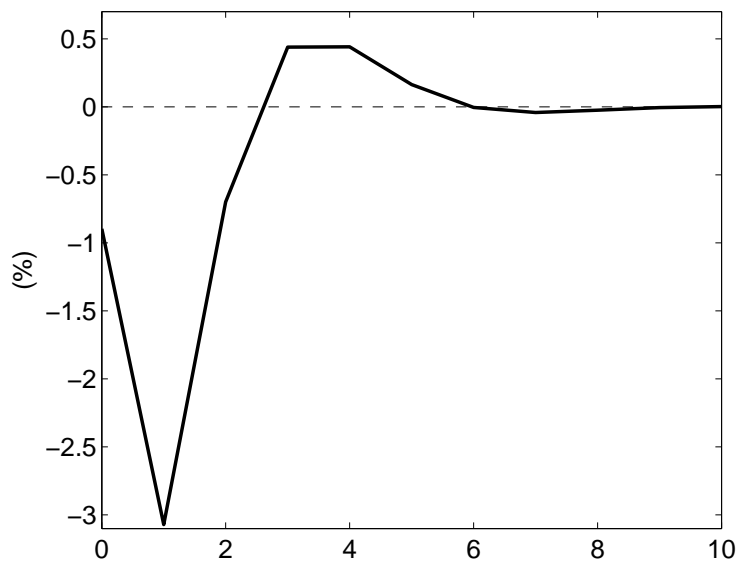

(c) Capital Investment Growth Response to Overall Uncertainty Shock

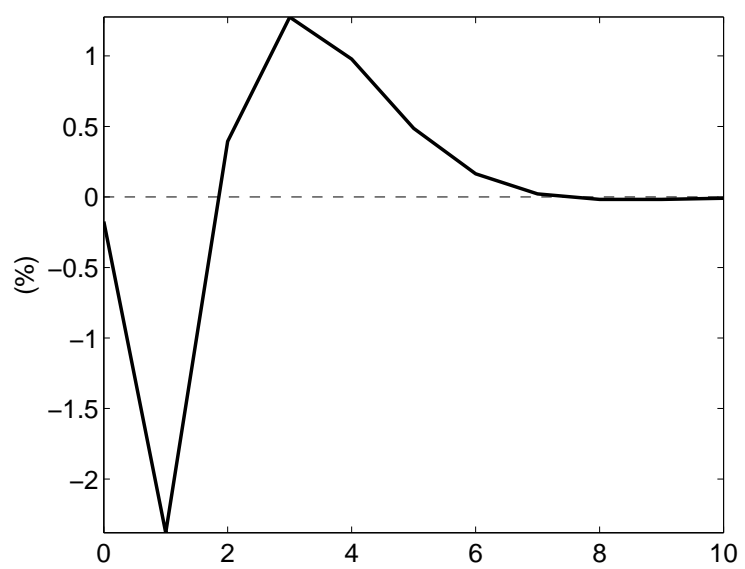

The Figure shows impulse responses of capital investment growth to one-standard deviation good, bad, and total uncertainty shocks. The impulse responses are computed from a VAR(1) which includes macroeconomic uncertainty measures (bad and good uncertainty for the first two panels, and total uncertainty for the last panel), expected consumption growth, and capital investment growth rate. Data are annual from 1930 to 2012. 


\section{Figure 8: Impulse Response of R\&D Investment to Macro Uncertainties}

(a) R\&D Investment Growth Response to Good Uncertainty Shock

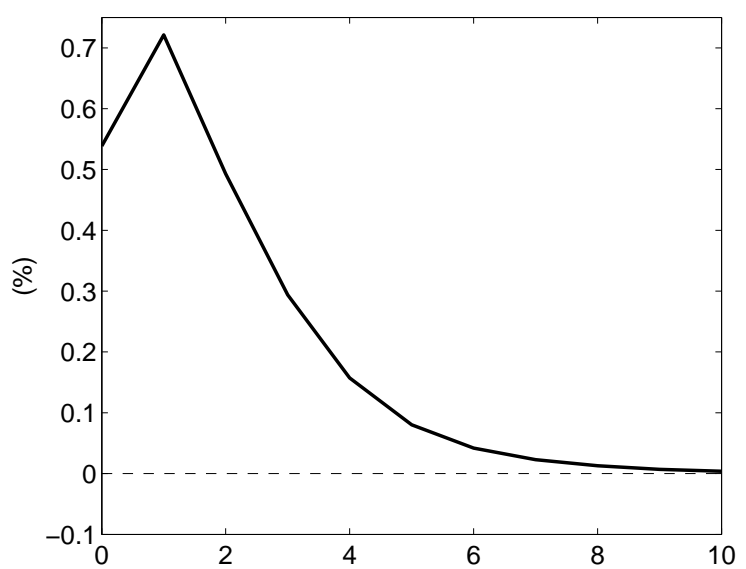

(b) R\&D Investment Growth Response to Bad Uncertainty Shock

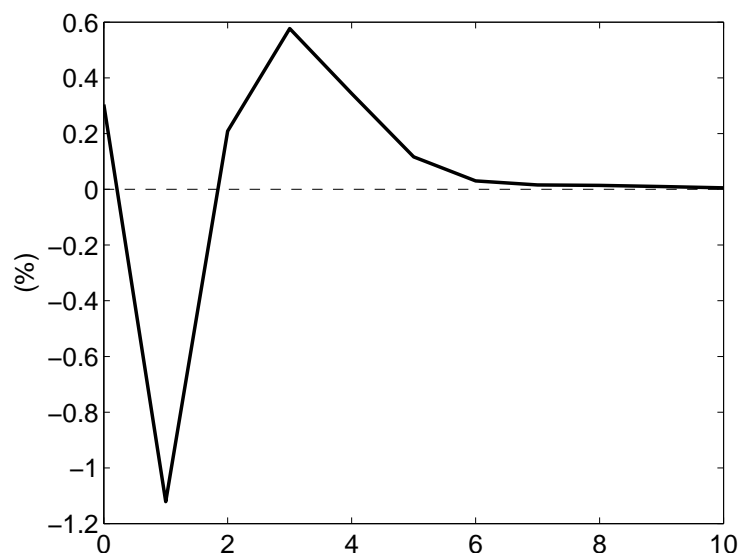

(c) R\&D Investment Growth Response to Overall Uncertainty Shock

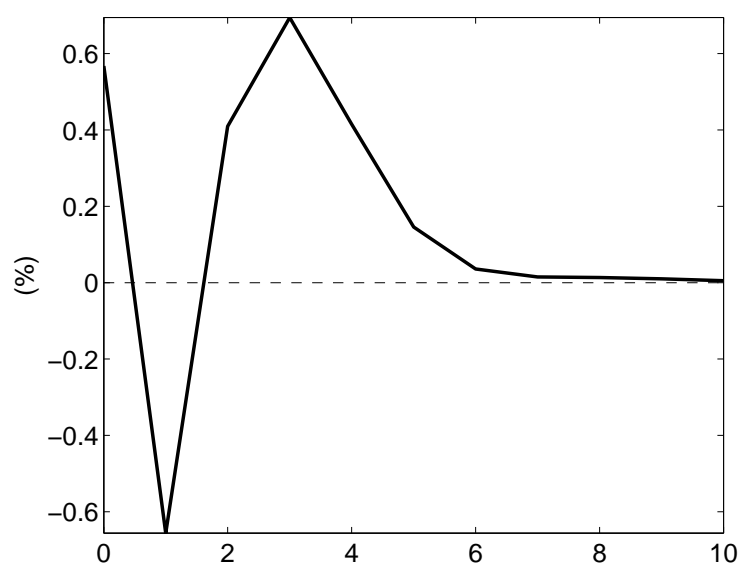

The Figure shows impulse responses of $\mathrm{R} \& \mathrm{D}$ investment growth to one-standard deviation good, bad, and total uncertainty shocks. The impulse responses are computed from a $\operatorname{VAR}(1)$ which includes macroeconomic uncertainty measures (bad and good uncertainty for the first two panels, and total uncertainty for the last panel), expected consumption growth, and R\&D investment growth rate. Data are annual from 1954 to 2007. 


\section{Figure 9: Impulse Response of Price-Dividend Ratio to Macro Uncertainties}

(a) Price-Dividend Ratio Response to Good Uncertainty Shock

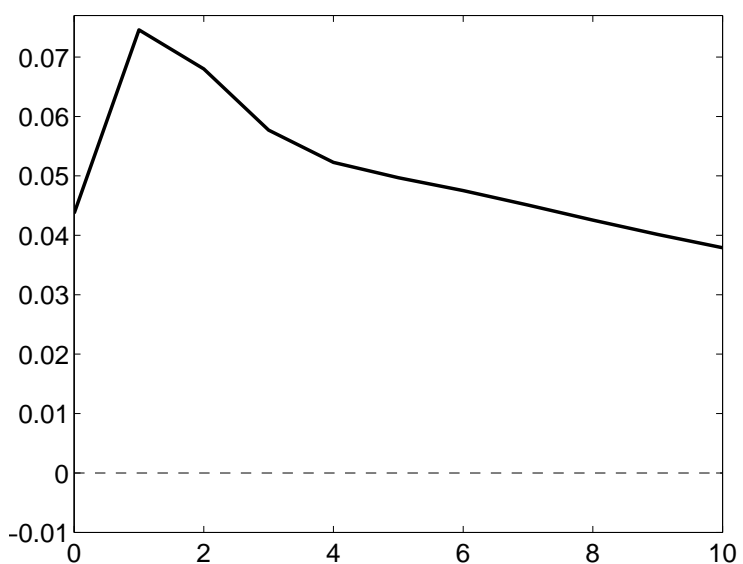

(b) Price-Dividend Ratio Response to Bad Uncertainty Shock

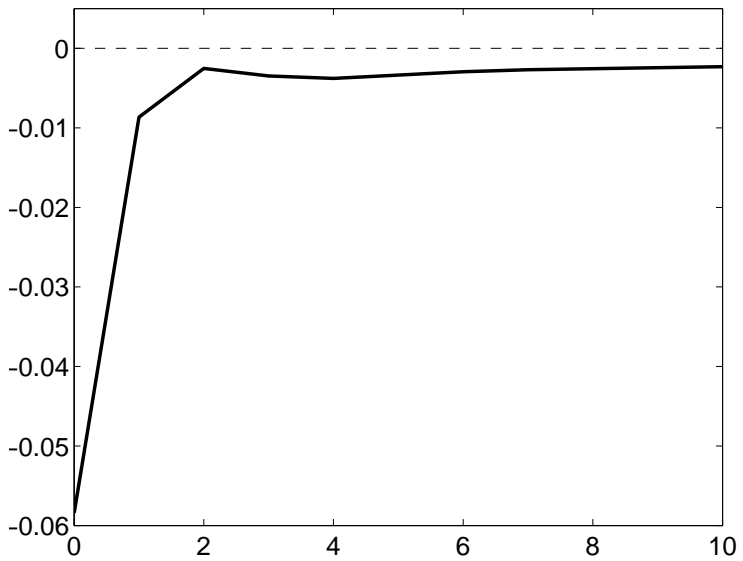

(c) Price-Dividend Ratio Response to Overall Uncertainty Shock

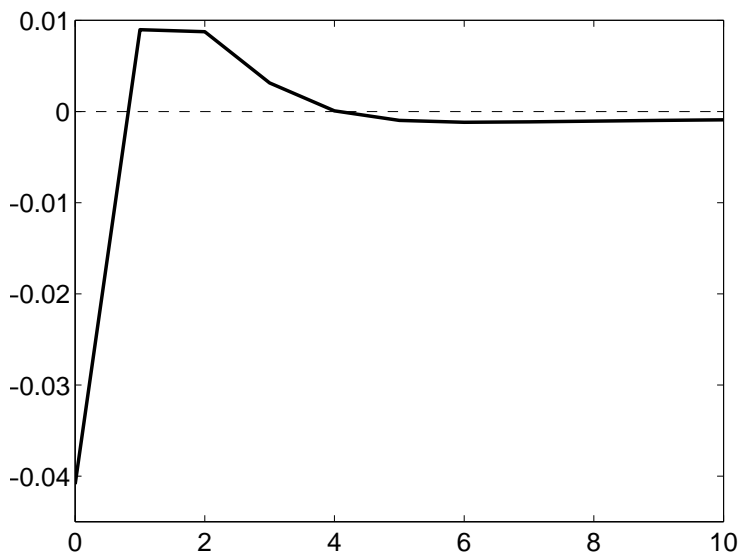

The Figure shows impulse responses of market price-dividend ratio to one-standard deviation good, bad, and total uncertainty shocks. The impulse responses are computed from a VAR(1) which includes macroeconomic uncertainty measures (bad and good uncertainty for the first two panels, and total uncertainty for the last panel), expected consumption growth, and the market pricedividend ratio. Data are annual from 1930 to 2012. 
Figure 10: Impulse Response of Price-Earnings Ratio to Macro Uncertainties

(a) Price-Earnings Ratio Response to Good Uncertainty Shock

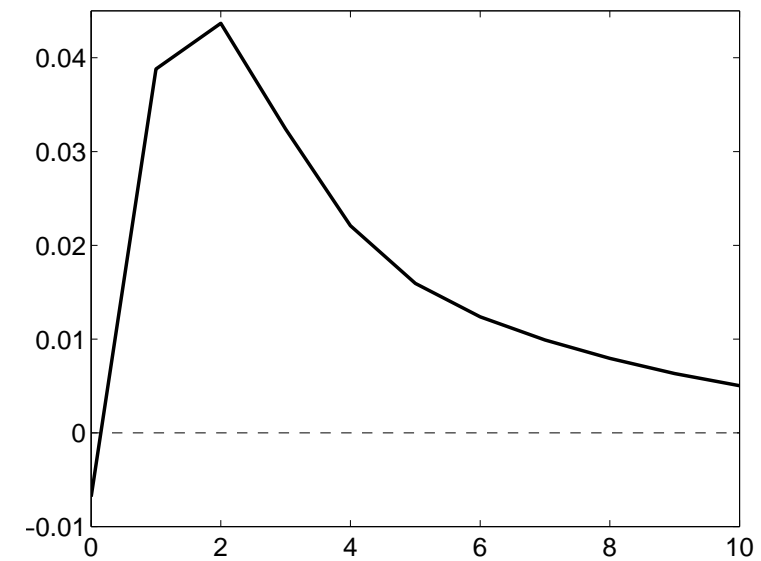

(b) Price-Earnings Ratio Response to Bad Uncertainty Shock

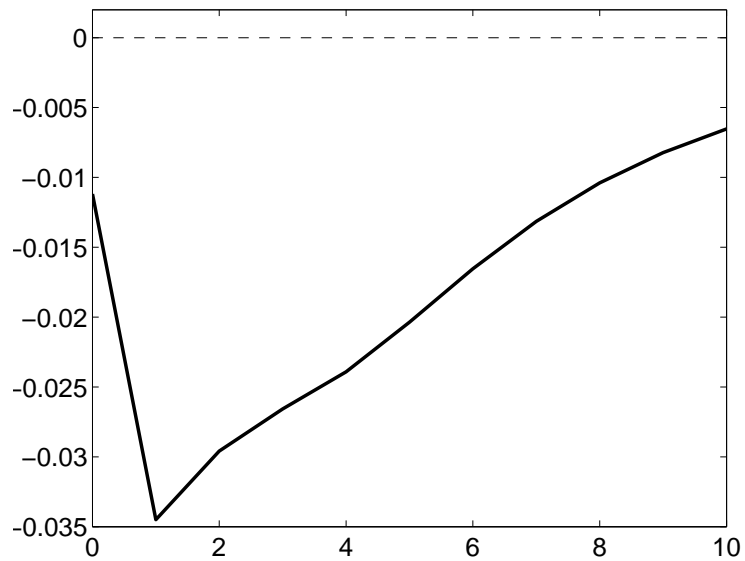

(c) Price-Earnings Ratio Response to Overall Uncertainty Shock

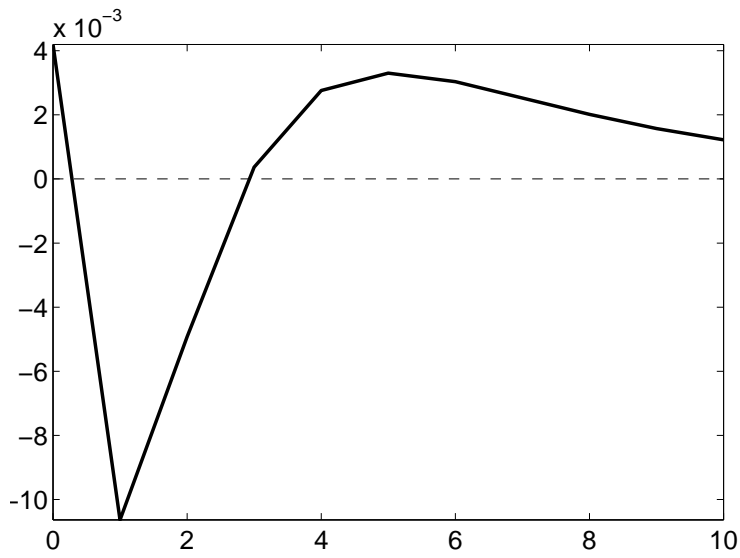

The Figure shows impulse responses of market price-earnings ratio to one-standard deviation good, bad, and total uncertainty shocks. The impulse responses are computed from a VAR(1) which includes macroeconomic uncertainty measures (bad and good uncertainty for the first two panels, and total uncertainty for the last panel), expected consumption growth, and the market priceearnings ratio. Data are annual from 1930 to 20120 